\title{
Surface Stability and Morphology of Calcium Phosphate Tuned by pH Values and Lactic Acid Additives: Theoretical and Experimental Study
}

Hongwei Chen, ${ }^{\# 1}$ Changchang Lv, ${ }^{\# 1}$ Lin Guo, ${ }^{* 1}$ Ming Ma, ${ }^{2}$ Xiangfeng Li, ${ }^{3}$ Zhengyi Lan, ${ }^{2}$ Jun Huo, ${ }^{4}$ Hao Dong, ${ }^{4}$ Xiangdong Zhu, ${ }^{3}$ Qiang Zhu, ${ }^{1}$ Yuming $G u,{ }^{1}$ Ziteng Liu, ${ }^{1}$ Jianjun Liu, ${ }^{2}$ Hangrong Chen, ${ }^{2}$ Xuefeng Guo, ${ }^{* 1}$ Jing Ma, ${ }^{* 1}$

${ }^{1}$ Key Laboratory of Mesoscopic Chemistry of Ministry of Education, School of Chemistry and Chemical Engineering, Nanjing University, Nanjing, 210023, P. R. China

${ }^{2}$ Shanghai Institute of Ceramics, Chinese Academy of Sciences, 200050, Shanghai, China

${ }^{3}$ National Engineering Research Center for Biomaterials, Sichuan University, Chengdu, 610064 , China.

${ }^{4}$ Kuang Yaming Honors School \& Institute for Brain Sciences, Nanjing University, Nanjing 210023, China

\# These two authors contributed equally to this work.

*Address correspondence to majing@nju.edu.cn (Prof. J. Ma); linguo@nju.edu.cn (Prof. L. Guo); guoxf@nju.edu.cn (Prof. X. Guo)

KEYWORDS: Nucleation, Calcium phosphate, Lactic acid, pH, Molecular dynamics simulations, High-throughput experimentations 
ABSTRACT: The ubiquitous mineralization of calcium phosphate $(\mathrm{CaP})$ facilitates biological organisms to produce hierarchically structured minerals. The coordination number and strength of $\mathrm{Ca}^{2+}$ ions with phosphate species, oxygen-containing additives, and solvent molecules played a crucial role in tuning nucleation processes and surface stability of $\mathrm{CaP}$ under the simulated body fluid (SBF) or aqueous solutions upon the addition of oligomeric lactic acid $\left(\mathrm{LAC}_{\mathrm{n}}, \mathrm{n}=1,8\right)$ and changing $\mathrm{pH}$ values. As revealed by ab initio molecular dynamics (AIMD), density functional theory (DFT), and molecular dynamics (MD) simulations as well as high-throughput experimentation (HTE), the binding of LAC molecules with $\mathrm{Ca}^{2+}$ ions and phosphate species could stabilize both pre-nucleation clusters and brushite (DCPD, $\mathrm{CaHPO}_{4} \cdot 2 \mathrm{H}_{2} \mathrm{O}$ ) surface through intermolecular electrostatic and hydrogen bonding interactions. When the concentration of $\mathrm{Ca}^{2+}$ ions $\left(\left[\mathrm{Ca}^{2+}\right]\right)$ is very low, the amount of the formed precipitation decreased with the addition of LAC based on UV-Vis spectroscopic analysis due to the reduced chance for the LAC capped $\mathrm{Ca}^{2+}$ ions to coordinate with phosphates and the increased solubility in acid solution. With the increasing $\left[\mathrm{Ca}^{2+}\right]$ concentration, the kinetically stable DCPD precipitation was obtained with high $\mathrm{Ca}^{2+}$ coordination number and low surface energy. Morphologies of DCPD precipitation are in plate, needle, or rod, depending on the initial $\mathrm{pH}$ values that tuned by adding $\mathrm{NH}_{3} \cdot \mathrm{H}_{2} \mathrm{O}, \mathrm{HCl}$, or $\mathrm{CH}_{3} \mathrm{COOH}$. The prepared samples at $\mathrm{pH} \approx 7.4$ with different $\mathrm{Ca} / \mathrm{P}$ ratios exhibited negative zeta potential values, which were correlated with the surface electrostatic potential distributions and potential biological applications. 


\section{INTRODUCTION}

Bones and teeth of vertebrates are known to come from mineralization of calcium phosphate $(\mathrm{CaP})^{1}$ through two possible nucleation processes, i.e., a classical aggregation or a two-step nucleation pathway. ${ }^{2}$ The real nucleation process of $\mathrm{CaP}$ in biological conditions becomes much more complicated, attracting extensive interest both experimentally and theoretically.

The first factor in controlling nucleation process of $\mathrm{CaP}$ is the $\mathrm{pH}$ value, which could affect the occurrence of different phosphate species, such as $\mathrm{H}_{3} \mathrm{PO}_{4}$ (called $3 \mathrm{H}$ for short), $\mathrm{H}_{2} \mathrm{PO}_{4}{ }^{-}(2 \mathrm{H}), \mathrm{HPO}_{4}{ }^{2-}(1 \mathrm{H})$, and $\mathrm{PO}_{4}{ }^{3-}(0 \mathrm{H})$, shown in Figure 1a. Thus, properties of $\mathrm{CaP}$ precipitation, ${ }^{3,4}$ adsorption of organic acid $^{5}$, phase composition ${ }^{6}$, morphology $y^{7,8}$, zeta potentials ${ }^{9-12}$, and crystal size of $\mathrm{CaP}^{13}$ could be varied with different $\mathrm{pH}$ values.

Secondly, through the modulation of interfacial interaction and kinetic stability, the introduction of many kinds of additives, such as metal ions, acid or basic solutions, amino acids, dopamine, and citrate, could change the nucleation or phase transformation paths and morphologies ${ }^{8,14-19}$. Starting from the ion pair $\mathrm{CaHPO}_{4}$ in a neutral or basic $\mathrm{CaP}$ solution, a Ca-deficient pre-nucleation cluster, $\mathrm{Ca}\left(\mathrm{HPO}_{4}\right)_{3}{ }^{4-}$, is formed at the early stage of nucleation process. ${ }^{20-24}$ Subsequently, those small-sized clusters could aggregate into thermodynamically metastable amorphous $\mathrm{CaP}$ phase $\left(\mathrm{ACP}, \mathrm{Ca}_{\mathrm{x}} \mathrm{H}_{\mathrm{y}}\left(\mathrm{PO}_{4}\right)_{\mathrm{z}} \cdot \mathrm{nH}_{2} \mathrm{O}, \mathrm{n}=3-4.5 ; 15-20 \% \mathrm{H}_{2} \mathrm{O}\right)^{3,25}$. The building blocks of ACP, such as post-nucleation cluster, $\mathrm{Ca}_{2}\left(\mathrm{HPO}_{4}\right)_{3}{ }^{2-}$, and Posner's cluster, $\mathrm{Ca} 9\left(\mathrm{PO}_{4}\right)_{6}{ }^{20,25-27}$, are further propagated with the increasing calcium content. Although ACP was a metastable phase, transmission electron microscopy (TEM) experiments suggested that the lifetime of ACP could be extended at $310 \mathrm{~K}$ by adding additive poly (aspartic acid). ${ }^{28}$ In basic solution, the formed ACP phase functions as the precursor, and then transforms into octocalcium phosphate $\left(\mathrm{OCP}, \mathrm{Ca}_{8}\left(\mathrm{HPO}_{4}\right)_{2}\left(\mathrm{PO}_{4}\right)_{4} \cdot 5 \mathrm{H}_{2} \mathrm{O}\right)$ and the most thermodynamically stable hydroxyapatite $\left(\mathrm{HA}, \mathrm{Ca}_{10}\left(\mathrm{PO}_{4}\right)_{6}(\mathrm{OH})_{2}\right)$ crystalline phase. ${ }^{20 \text {, }}$ ${ }^{25}$ In acid solution, the calcium-deficient minerals $(\mathrm{Ca} / \mathrm{P}<1.67)$ such as monocalcium 
phosphate monohydrate $(\mathrm{MCPM}, \mathrm{Ca} / \mathrm{P}=0.50)$ and dicalcium phosphate dihydrate $(\mathrm{DCPD}, \mathrm{Ca} / \mathrm{P}=1.00)$ could be formed with $\mathrm{pH}=0.0 \sim 6.0$ at $298 \mathrm{~K} .^{3}$

Despite a thermodynamically metastable species relative to HA, DCPD (also called brushite) has been widely applied to pathological calcifications and gentle polishing agents in toothpastes. ${ }^{29-31}$ DCPD is also an important component of bone cement in bone repair due to its faster resorption than apatite. ${ }^{32,33}$ Recently, a new CaP cement with $\mathrm{Ca} / \mathrm{P}$ ratio of 1.38 , consisting of the mixed components of $\alpha$-tricalcium phosphate, HA, and DCPD, was produced by the rapid addition of solution $\mathrm{Ca}\left(\mathrm{NO}_{3}\right)_{2} \cdot 4 \mathrm{H}_{2} \mathrm{O}$ to the stirring solution $\left(\mathrm{NH}_{4}\right)_{2} \mathrm{HPO}_{4}$ with $\mathrm{pH}=4.5-5$ at room temperature. ${ }^{32}$ DCPD could be easily crystallized in acid solution $(\mathrm{pH}=2.0 \sim 6.0)^{4}$ from aqueous solutions containing soluble calcium salts $\left(\mathrm{Ca}\left(\mathrm{NO}_{3}\right)_{2} \cdot 4 \mathrm{H}_{2} \mathrm{O}, \mathrm{CaCl}_{2} \cdot 2 \mathrm{H}_{2} \mathrm{O}\right.$, $\left.\mathrm{Ca}\left(\mathrm{CH}_{3} \mathrm{COO}\right)_{2} \cdot \mathrm{H}_{2} \mathrm{O}\right)$ and phosphate salts $\left(\mathrm{NH}_{4} \mathrm{H}_{2} \mathrm{PO}_{4},\left(\mathrm{NH}_{4}\right)_{2} \mathrm{HPO}_{4}, \mathrm{Na}_{2} \mathrm{HPO}_{4}\right.$, $\mathrm{NaH}_{2} \mathrm{PO}_{4}, \mathrm{KH}_{2} \mathrm{PO}_{4}$, or $\left.\mathrm{K}_{2} \mathrm{HPO}_{4}\right)^{8,15,34-37}$ at room temperature and $\mathrm{Ca} / \mathrm{P}$ ratio of 1.00 . The morphology of DCPD changed with additives, initial $\mathrm{pH}$ values, and ion concentrations. ${ }^{8,34}$ Additives could also affect the solubility of $\mathrm{CaP}$ phases. For example, citric acid significantly inhibited the dissolution of HA, but had little influence on the dissolution of DCPD at $37{ }^{\circ} \mathrm{C}(\mathrm{pH}=5.50) .{ }^{38}$ The applications of DCPD in the biomedical, food, and many other fields face the challenge of precise control of crystalline structure and properties due to various possible phase transformations of 'active' DCPD in presence of different additives and physiological environments. For example, DCPD can transform into DCPA $\left(\mathrm{CaHPO}_{4}\right)$ at temperature above $\sim 80{ }^{\circ} \mathrm{C} .{ }^{4}$ This transformation is accompanied by structural changes ${ }^{39}$ and decrease in volume ( $11 \%)^{40}$. Under physiological conditions, the formation of DCPD was more feasible than HA. In water, DCPD was also not kinetically stable as HA. The kinetic stability and interfacial energy of DCPD were modulated with the $\mathrm{pH}$ value of the solution and additives (such as acidic amino acids). ${ }^{14,16,18}$ A question is then raised: is it possible to draw a correlation between the kinetical stability of DCPD precipitation and interfacial interactions under different experimental conditions or with different additives? To answer this question, the nucleation process of DCPD is systematically investigated by 
DFT, AIMD, and MD simulations as well as high-throughput experimentations (HTE) based on the four tunable factors, i.e., oxygen-containing additive, $\mathrm{Ca} / \mathrm{P}$ ratio, solvent, and $\mathrm{pH}$ value, respectively (Figure $1 \mathrm{~b}$ and Figure 2).

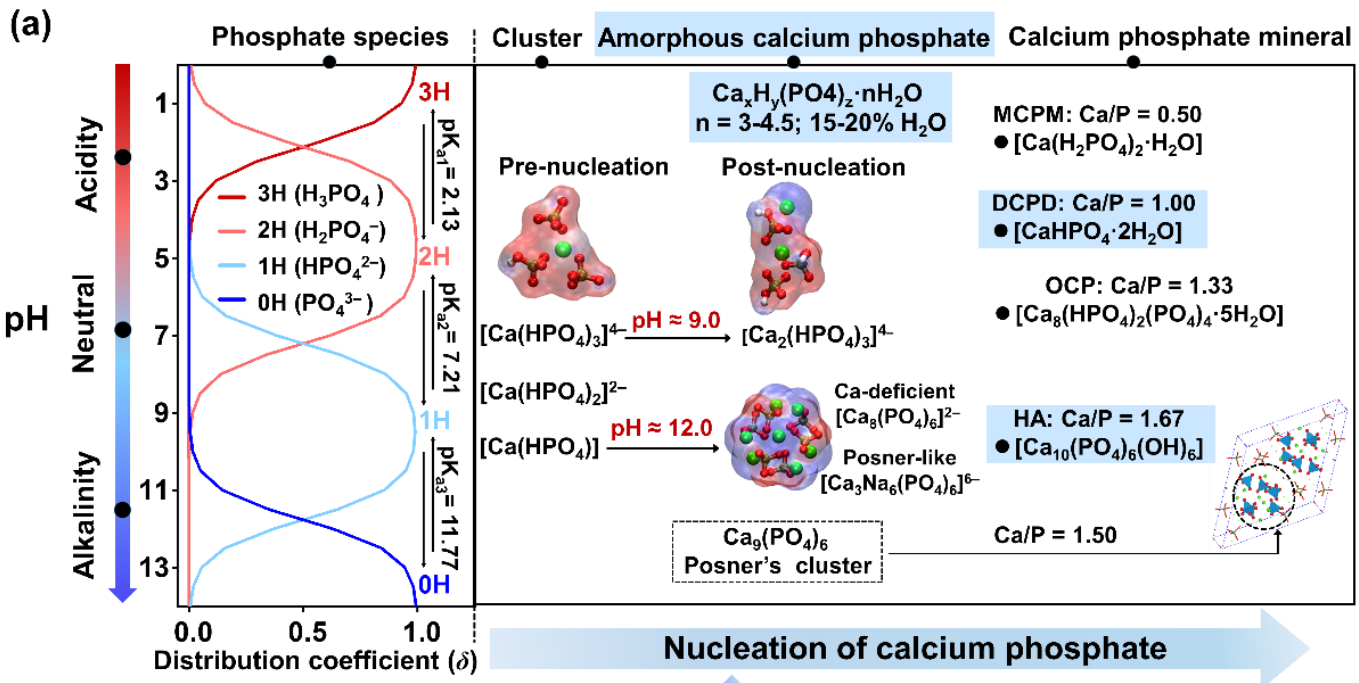

(b)

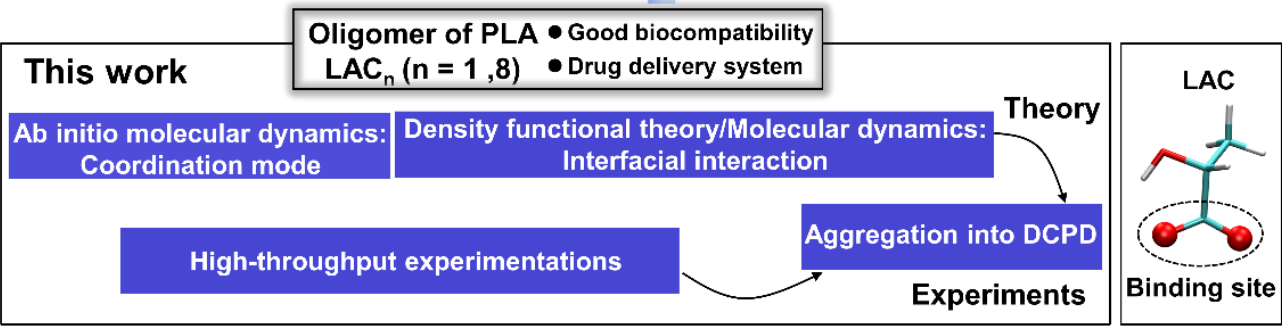

Figure 1. (a) The distribution coefficient $\delta$ of phosphate species, $\mathrm{H}_{3} \mathrm{PO}_{4}(3 \mathrm{H}), \mathrm{H}_{2} \mathrm{PO}_{4}{ }^{-}$ $(2 \mathrm{H}), \mathrm{HPO}_{4}{ }^{2-}(1 \mathrm{H})$, and $\mathrm{PO}_{4}{ }^{3-}(\mathrm{OH})$, as a function of $\mathrm{pH}$ values, and the schematic illustration of nucleation process of $\mathrm{CaP}$, (b) The influences of $\mathrm{LAC}_{\mathrm{n}}(\mathrm{n}=1,8)$ additives and $\mathrm{pH}$ values on the nucleation are investigated in this work through theoretical (AIMD, DFT, and MD) and experimental (UV-Vis, XRD, TEM, and Zeta potential) study. Color codes: $\mathrm{Ca}=$ green; $\mathrm{O}=$ red; $\mathrm{P}=\tan ; \mathrm{C}=$ cyan; $\mathrm{H}=$ white.

The reason of choosing LAC as the additive prototype in the present work is threefold. Firstly, LAC is the basic block of PLA (polylactic acid), which is one of the widely used biodegradable polyesters in medical applications of tissue engineering, wound management, drug delivery system, and orthopedic device. ${ }^{41}$ Since PLA is insoluable 
in mild experimental conmditions, we adopt the water-soluble LAC oligomer as a simplified model in the study of the interfacial interaction and biocompatibility with $\mathrm{CaP}$ systems, which are also implantable biomaterials for bone repair and tissue regeneration. Secondly, some $\mathrm{CaP}$ materials such as hydroxyapatite nanoparticle (HANP) could inhibit the proliferation of some kinds of tumor cells ${ }^{42-47}$. We are hence curious about the interaction of HA and DCPD with LAC, which is a by-product of aerobic or anaerobic glycolysis. Since the high amount of LAC is a characteristic feature of tumor cells, ${ }^{48}$ LAC could also function as a key signaling molecule in detecting cancer cell migration, angiogenesis and metastasis. ${ }^{49}$ Thirdly, LAC not only bears three oxygen atoms $\left(\mathrm{C}_{3} \mathrm{H}_{6} \mathrm{O}_{3}\right.$, one in hydroxyl group and the other two from carboxyl group) to bind with CaP clusters, but also works as an acidic solvent, which will be demonstrated to facilitate the formation or dissolution of DCPD precipitation depending on the concentrations of LAC and $\mathrm{Ca}^{2+}$ ions.

With an emphasis laid on DCPD and LAC additive, we employed DFT to depict the interfacial interactions of additive with $\mathrm{CaP}$ clusters and surface with different $\mathrm{Ca} / \mathrm{P}$ ratios. AIMD and MD simulations demonstrated the aggregation processes of $\mathrm{CaP}$ clusters with and without (w/o) LAC oligomers $\left(\mathrm{LAC}_{\mathrm{n}}, \mathrm{n}=1,8\right)$ in different solutions. $\mathrm{HTE}^{50}$ allowed a large number of experiments on changing the $\mathrm{Ca} / \mathrm{P}$ ratios, additives, and solvents to be executed in parallel (Figure 2). It will be also revealed that the coordination number of $\mathrm{Ca}^{2+}$ ions, $\mathrm{N}_{\text {Ca-contact }},{ }^{51}$ is an important descriptor to rationalize the relative surface stability and nucleation process of DCPD under different biological conditions. The theoretical and experimental results are useful to comprehend the modulation of interfacial interactions of the CaP-additive and size/morphology of $\mathrm{CaP}$ samples. 
(a)

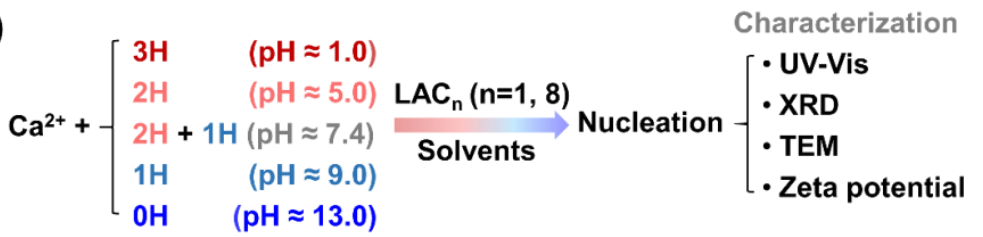

(b) Molecular simulations: MD and AIMD

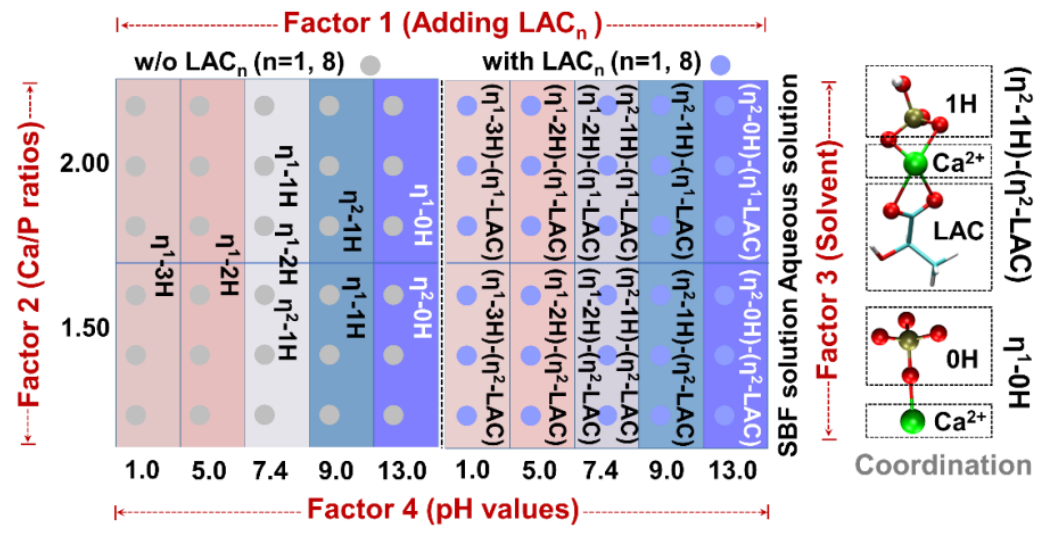

(c) High-throughput experimentations

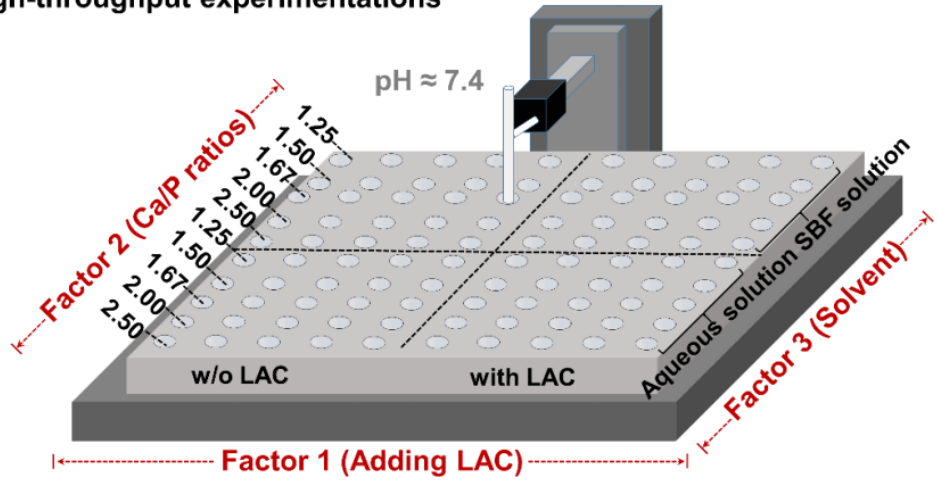

Figure 2. (a) The model build and experimental detection methods in studied systems, (b) the main factors affecting the nucleation of $\mathrm{CaP}$, (c) schematic diagram of highthroughput experimentations equipment. Color codes: $\mathrm{Ca}=$ green; $\mathrm{O}=$ red; $\mathrm{P}=\tan ; \mathrm{C}$ = cyan; $\mathrm{H}=$ white .

\section{MATERIALS AND METHODS}

\subsection{Binding strength estimated by DFT calculations.}

To study the influence of $\mathrm{pH}$ values and the addition of LAC on interfacial interactions of $\mathrm{CaP}$ with the surrounding species, the binding strength of $\mathrm{Ca}^{2+}(M)$ with the ligand $(Y)$, including phosphate species, carbonate species in SBF solution, LAC 
oligomers, and solvent molecules (water or $\mathrm{CH}_{3} \mathrm{COOH}$ ), was calculated by using DFT with implicit solvation model density (SMD) and polarizable continuum model (PCM) at the level of M062X/6-311+g(d,p) within the Gaussian 16 package $^{52}$. The binding free energy, $\Delta G_{b i n d}$, of a $\mathrm{CaP}$ cluster in a certain $\mathrm{pH}$ condition was derived from the following equation.

$$
G_{b i n d}=G_{M Y}+6 \times G_{w t}-G_{Y}-G_{M(w t)_{6}}
$$

where $\mathrm{M}=\mathrm{Ca}^{2+}$, whose 6 -coordinated complexation with water (wt), $\mathrm{M}(\mathrm{wt}){ }_{6}{ }^{2+}$, is taken as a reference in binding Gibbs free energy calculations. The optimized geometries of the studied systems were presented in Figure S1 and the calculated Gibbs free energies at $298 \mathrm{~K}$ were listed in Table S1 and Table S2. A negative value of $\Delta G_{b i n d}$ of a complex indicates that this compound is thermodynamically more stable than the $\mathrm{Ca}(\mathrm{wt}) 6^{2+}$ complex, causing the competitive interaction with $\mathrm{Ca}^{2+}$ ions in the presence of various additives (S1 of supporting information). In $\mathrm{Ca}(\mathrm{wt})_{6}{ }^{2+}$ complex, the coordination number, $\mathrm{N}_{\text {Ca-contact }}=6$. It will be shown later that the coordination number is an indicator of binding strength in $\mathrm{CaP}$ systems.

With an increase in the cluster size, crystallization may take place after some treatments. The crystal or slab model with periodic boundary condition (PBC), shown in Tables S3-S6, was applied to simulate the binding of additives ( $\mathrm{LAC}$ or $\mathrm{CH}_{3} \mathrm{COOH}$ ) on the DCPD or HA surface using DFT calculations with the plane wave-based Vienna ab initio simulation package $(\mathrm{VASP})^{53}$. DFT calculations were performed within generalized gradient approximation (GGA) with Perdew-Burke-Ernzerhof (PBE) $)^{54}$ functional. The van der Waals (vdW) correction with the Grimme approach (DFT-D3) $)^{55}$ was performed to describe the interaction between the additive species and surfaces. The relative stability of surface was estimated by its surface energy, $E_{\text {surf }}$, (S2 of supporting information: Table S4). To estimate the interaction energy between additives and $\mathrm{DCPD}$ or $\mathrm{HA}$ slab with different $\mathrm{Ca} / \mathrm{P}$ ratios, the binding energies $\left(E_{\text {bind }}\right)$ were calculated from the energy difference between the whole system and the individual components (S3 of supporting information: Table S5, Table S6 and Table S7). 
2.2. MD simulations of aggregation and nucleation. To study the nucleation process of $\mathrm{CaP}$ in SBF solution (Table S8) w/o or with oligomeric $\mathrm{LAC}_{\mathrm{n}}(\mathrm{n}=1,8)$ additives, we carried out the MD simulations by using AMBER16 (CUDA version) ${ }^{56}$. The octamer $\mathrm{LAC}_{8}$ was taken as an example to model the interfacial interaction of PLA polymer with the CaP clusters. Considering the $p K_{a}$ values of LAC $\left(3.86^{57}\right)$ and PLA $\left(3.10^{58}\right)$, the deprotonated LAC/PLA form (also called LAC/PLA for short) is the dominated species in the studied $\mathrm{pH}$ conditions except for the simulation with $\mathrm{pH} \approx 1.0$ (Figure $1 \mathrm{~b}$ and Figure $\mathrm{S} 2$ ). In addition, there are several kinds of anions in SBF solution, such as carbonate ions (Figure S3), whose protonation state distribution at different $\mathrm{pH}$ values depends on their $p K_{a}$ values ${ }^{59-61}$. The GAFF2 force field was used for the phosphate species, with the force field parameters shown in Table S9. The 500 ns MD simulations were run at NPT ensemble (with the constant pressure of 1.0 bar and temperature of $300 \mathrm{~K}$ ) for the model systems with different $\mathrm{pH}$ values and $\mathrm{Ca} / \mathrm{P}$ ratios, as shown in Tables S10-S15. The temperature was controlled using Langevin dynamics ${ }^{61}$ with the collision frequency of $1 \mathrm{ps}^{-1}$. Integration step was set as $1 \mathrm{fs}$. The direct spatial nonbonded cutoff of $8.0 \AA$ was used. The local binding modes were displayed from the radial distribution function (RDF) and spatial distribution function (SDF) using $\mathrm{VMD}^{62}$ and TRAVIS ${ }^{63}$ programs, respectively. Adaptive PoissonBoltzmann Solver (APBS) ${ }^{64}$ was employed to study the electrostatic properties of CaP clusters (S4 of supporting information).

2.3. AIMD simulations for exploring the local coordination modes. In order to provide the more detailed information of the intermolecular interaction in the early aggregation stage, the AIMD simulations were carried out using CP2 $\mathrm{K}^{65}$ with PBE functional and GTH-DZVP basis set ${ }^{66}$ for all atoms. The Grimme algorithm (DFT-D3) was employed to improve the description of van der Waals (vdW) interactions. The energy cutoff for plane wave basis set was $550 \mathrm{Ry}$. Several CaP systems with different protonation conditions (Table S16) with or w/o the addition of LAC were set by using the Packmol code ${ }^{67}$ in a periodic boundary condition $(\mathrm{PBC})$ cell of $14 \times 14 \times 14 \AA^{3}$ to illustrate the coordination modes between different phosphate species and $\mathrm{Ca}^{2+}$ ions 
under different $\mathrm{pH}$ values. The counterions, $\mathrm{Na}^{+}$or $\mathrm{Cl}^{-}$ions, were added to neutralize the excess charge. The 20 ps AIMD trajectory was generated in an NPT ensemble at $300 \mathrm{~K}$ and 1 bar with a time step of $0.5 \mathrm{fs}$.

2.4. High-throughput experimentation (HTE) for various factor combinations. The HTE were carried out using the house-made synthesis equipment (Figure 2c and Figure S4). Based on combinatoric chemistry method, we developed a high-through microarray synthesis equipment which is composed of a multi-channel sample collection platform, a multi-channel automatic liquid injection system, and an automatic stirring system. The addition of reaction solution, the stirring speed and the stepping of XY-axis motion guide can be controlled by the computer with our selfcompiled operating software. Therefore, the input ratio of different reactants, the $\mathrm{pH}$ value of solution, reaction temperature and stirring time can be auto-executed by preset system. Through this equipment, different samples can be automatically synthesized one by one (S5 of supporting information: Tables S17-S24).

To prepare the solution with $\mathrm{Ca}^{2+}$ concentration $\left(\left[\mathrm{Ca}^{2+}\right]\right)$ of about $0.01 \mathrm{~mol} \cdot \mathrm{dm}^{-3}$ and $0.3 \mathrm{~mol} \cdot \mathrm{dm}^{-3}$, calcium chloride $\left(\mathrm{CaCl}_{2} \cdot 2 \mathrm{H}_{2} \mathrm{O}\right)$ and diammonium hydrogen phosphate $\left(\left(\mathrm{NH}_{4}\right)_{2} \mathrm{HPO}_{4}\right)$ were purchased from Sinopharm Chemical Reagent Co., Ltd. The SBF solution was directly acquired from Shanghai Yuanye Bio-technology Co., Ltd. To test the effect of $\mathrm{Mg}^{2+}$ ions on the nucleation, $\mathrm{Ca} / \mathrm{Mg}$-deficient Dulbecco's phosphate-buffered saline (DPBS) solution was purchased from Shanghai Aladdin BioChem Technology Co., Ltd., which also provided the commercial DCPD $\mathrm{CaHPO}_{4} \cdot 2 \mathrm{H}_{2} \mathrm{O}$ (JCPDS\#09-0077, AR, $99.0 \%$ ), called DCPD-C, for comparison with the as-prepared DCPD samples under SBF (named as DCPD-S) and DPBS (DCPD-D) solutions in this work. The species of LAC used as factor 1 in the CaP nucleation experiments was provided by Shanghai Aladdin Bio-Chem Technology Co., Ltd. For the experiments under high $\mathrm{Ca}^{2+}$ concentration with $\left[\mathrm{Ca}^{2+}\right]=0.1 \mathrm{~mol} \cdot \mathrm{dm}^{-3}, \mathrm{LAC}$ (purity $\geq 95 \%), \mathrm{CaCl}_{2} \cdot 2 \mathrm{H}_{2} \mathrm{O},\left(\mathrm{NH}_{4}\right)_{2} \mathrm{HPO}_{4}$, and $\mathrm{SBF}$ solution were purchased from Shanghai Bide Chemical Reagent Co,. Ltd., Shanghai Hushi Chemical Reagent Co., Ltd., and Phygene Life Sciences Co., Ltd., respectively. For cases using very high concentration 
of $\left[\mathrm{Ca}^{2+}\right]=0.86 \mathrm{~mol} \cdot \mathrm{dm}^{-3}, \mathrm{CH}_{3} \mathrm{COOH}, \mathrm{H}_{3} \mathrm{PO}_{4}$ and $\mathrm{Ca}(\mathrm{OH})_{2}$ were purchased from Shanghai Hushi Chemical Reagent Co., Ltd., Shanghai Aladdin Bio-Chem Technology Co., Ltd. and Shanghai Aladdin Bio-Chem Technology Co., Ltd., respectively. All chemicals were used without further purification.

$\mathrm{XRD}$ analysis for the crystalline structures of the as-prepared products were conducted on a Shimadzu XRD-6000 instrument with $\mathrm{Cu} K \alpha$ radiation $(\lambda=0.154 \mathrm{~nm})$ generated at $40 \mathrm{kV}$ and $30 \mathrm{~mA}$. TEM images were obtained on JEOL JEM-1011 instrument with an accelerating voltage of $120 \mathrm{kV}$ to analyze the morphological and structural features of the as-made samples $\left(\left[\mathrm{Ca}^{2+}\right] \approx 0.1 \mathrm{~mol} \cdot \mathrm{dm}^{-3}\right)$. For the prepared samples with different $\mathrm{Ca} / \mathrm{P}$ ratios $\left(\left[\mathrm{Ca}^{2+}\right] \approx 0.3 \mathrm{~mol} \cdot \mathrm{dm}^{-3}\right)$ and the introduction of $\mathrm{CH}_{3} \mathrm{COOH}(1.0 \mathrm{~g}, 0.6 \mathrm{~g}, 0.2 \mathrm{~g}$ and $0.0 \mathrm{~g})$ in aqueous solutuon, the XRD patterns were characterized by Rigaku Ultima IV with $\mathrm{Cu} \mathrm{K \alpha}$ radiation at $40 \mathrm{kV}$ and $40 \mathrm{~mA}$. The morphology of the products was analyzed by field emission scanning electron microscopy (FETEM) on Libra 200 FE from Zeiss with an acceleration voltage of 200 $\mathrm{kV}$. Zeta potential analysis was performed at room temperature on Zetasizer (Nano-Z, Malvern, UK) based on dynamic light scattering theory. The morphology and energydispersive X-ray spectroscopy (EDS) mapping images of the three DCPD samples, DCPD-S, DCPD-D, and DCPD-C, respectively, were characterized by scanning electron microscopy (SEM, Shimadzu SSX-550) operating at $20 \mathrm{kV}$. The compositions of samples were detected by inductively coupled plasma atomic emission spectroscopy (ICP-AES, Perkin Elmer Avio500).

\section{RESULTS AND DISCUSSION}

\subsection{Protonation states of phosphate species under different $\mathrm{pH}$ values}

As shown in Figure 1a, the phosphate has different protonation states $(3 \mathrm{H}, 2 \mathrm{H}, 1 \mathrm{H}$, $\mathrm{OH})$ under different $\mathrm{pH}$ conditions, whose distribution coefficients could be derived from the following acid-base equations:

$$
\mathrm{H}_{3} \mathrm{PO}_{4} \rightleftharpoons \mathrm{H}^{+}+\mathrm{H}_{2} \mathrm{PO}_{4}^{-} \quad p K_{a l}=2.125
$$




$$
\begin{array}{ll}
\mathrm{H}_{2} \mathrm{PO}_{4}^{-} \rightleftharpoons \mathrm{H}^{+}+\mathrm{HPO}_{4}^{2-} & p K_{a 2}=7.208 \\
\mathrm{HPO}_{4}^{2-} \rightleftharpoons \mathrm{H}^{+}+\mathrm{PO}_{4}^{3-} & p K_{a 3}=11.770
\end{array}
$$

The $p K_{a 1}, p K_{a 2}$ and $p K_{a 3}$ in equations (2)-(4) are the acid dissociation constants of phosphate ${ }^{59}$. According to those $p K_{a}$ values, one could predict the distribution coefficient $\delta$, of each protonation state at a certain $\mathrm{pH}$ value by using the following equations:

$$
\begin{aligned}
& \delta(3 \mathrm{H})=\frac{\left[H^{+}\right]^{3}}{\left[H^{+}\right]^{3}+K_{a 1}\left[H^{+}\right]^{2}+K_{a 1} K_{a 2}\left[H^{+}\right]+K_{a 1} K_{a 2} K_{a 3}} \\
& \delta(2 \mathrm{H})=\frac{K_{a 1}\left[H^{+}\right]^{2}}{\left[H^{+}\right]^{3}+K_{a 1}\left[H^{+}\right]^{2}+K_{a 1} K_{a 2}\left[H^{+}\right]+K_{a 1} K_{a 2} K_{a 3}} \\
& \delta(1 \mathrm{H})=\frac{K_{a 1} K_{a 2}\left[H^{+}\right]}{\left[H^{+}\right]^{3}+K_{a 1}\left[H^{+}\right]^{2}+K_{a 1} K_{a 2}\left[H^{+}\right]+K_{a 1} K_{a 2} K_{a 3}} \\
& \delta(0 \mathrm{H})=\frac{K_{a 1} K_{a 2} K_{a 3}}{\left[H^{+}\right]^{3}+K_{a 1}\left[H^{+}\right]^{2}+K_{a 1} K_{a 2}\left[H^{+}\right]+K_{a 1} K_{a 2} K_{a 3}}
\end{aligned}
$$

Here, the $\left[\mathrm{H}^{+}\right]$represents the concentration of the $\mathrm{H}^{+}$ion in phosphate aqueous solution. Following the above equations, the $\mathrm{pH}$-dependent coefficients of different protonation states $(3 \mathrm{H}, 2 \mathrm{H}, 1 \mathrm{H}$, and $0 \mathrm{H})$ were plotted in Figure 1a. It is clear that phosphate solution is a mixture of different protonation states under certain $\mathrm{pH}$ condition. For example, each of $1 \mathrm{H}$ and $2 \mathrm{H}$ accounted for approximately half with the $\mathrm{pH} \approx 7.2$.

When those differently protonated phosphate species meet the $\mathrm{Ca}^{2+}$ ions, different kinds of minerals, ${ }^{68}$ such as TCP $\left(\mathrm{Ca}_{3}\left(\mathrm{PO}_{4}\right)_{2}\right), \mathrm{MCPM}$, and DCPD, would be formed with the difference in the $\mathrm{Ca} / \mathrm{P}$ ratio. The formation of those solid $\mathrm{CaP}$ preciptitations is controlled by the following solid-liquid equilibrium equations.

$$
\begin{array}{ll}
\mathrm{Ca}_{3}\left(\mathrm{PO}_{4}\right)_{2} \rightleftharpoons 3 \mathrm{Ca}^{2+}+2 \mathrm{PO}_{4}^{3-} & K_{s p}=2.20 \times 10^{-30} \\
\mathrm{CaHPO}_{4} \cdot 2 \mathrm{H}_{2} \mathrm{O} \rightleftharpoons \mathrm{Ca}^{2+}+\mathrm{HPO}_{4}^{2-}+2 \mathrm{H}_{2} \mathrm{O} & K_{s p}=2.19 \times 10^{-7} \\
\mathrm{Ca}\left(\mathrm{H}_{2} \mathrm{PO}_{4}\right)_{2} \cdot \mathrm{H}_{2} \mathrm{O} \rightleftharpoons \mathrm{Ca}^{2+}+2 \mathrm{H}_{2} \mathrm{PO}_{4}^{-}+\mathrm{H}_{2} \mathrm{O} & K_{s p}=1.00 \times 10^{-1.14}
\end{array}
$$

The $K_{s p}$ in equations (9)-(11) represents the solubility product ${ }^{69,70}$. The $\mathrm{pH}$ value affects the above equations, since the concentration of 'free' dissociated phosphate species in 
equations (5)-(8) is also determined by the $p K_{a}$ and $\mathrm{pH}$ values shown in equations (2)(4). Accordingly, the concentration of 'free' unbound $\mathrm{Ca}^{2+}$ ions could be derived from the $K_{s p}$ values of phosphate species. Such a concentration is a useful parameter in designing an experiment: once the real $\left[\mathrm{Ca}^{2+}\right]$ exceeded this value, the $\mathrm{CaP}$ precipitation would immediately occur in the solution.

\subsection{Interfacial interactions of LAC with CaP clusters}

Coordination of calcium ions with phosphates. The different phosphate protonation states had different binding capacities with $\mathrm{Ca}^{2+}$ ions, as shown in Figure 3a. Through increasing the $\mathrm{pH}$ value, the coordination between differently protonated phosphate species and $\mathrm{Ca}^{2+}$ is changed from the monodentate $\left(\eta^{1}\right)$ to the coexisting monodentate and bidentate $\left(\eta^{2}\right)$ modes. At the same time, the binding free energies ( $\Delta G_{\text {bind }}$ ) of the complexes of phosphate species with $\mathrm{Ca}^{2+}$ ions gradually increased as the $\mathrm{pH}$ value increases, indicating that the exposed oxygen atoms of the deprotonated phosphate state with negative partial charges were more affinitive to the positively charged $\mathrm{Ca}^{2+}$ ions than the protonated ones. The $\mathrm{Ca}\left(\eta^{2}-0 \mathrm{H}\right)$ cluster had the largest binding free energy $(-47.56 \mathrm{kcal} / \mathrm{mol})$, demonstrating that the $\eta^{2}$ combination of $\mathrm{Ca}^{2+}$ ions with $\mathrm{OH}$ ion in alkaline condition was the most favorable. For $\mathrm{OH}$ and $1 \mathrm{H}$ species, the binding free energies with $\mathrm{Ca}^{2+}$ ions by $\eta^{2}$ mode were larger than those of the complexation in $\eta^{1}$ mode, which would be correlated with the charge transfer $(C T)$ extent in the following subsection. The charge difference of $\mathrm{Ca}$ atom between the free $\mathrm{Ca}^{2+}$ ion and the bound $\mathrm{Ca}$ in $\mathrm{CaP}$ complex is used to evaluate the extent of $C T$, called $\Delta C T_{\mathrm{Ca}}$ (Figure $3 \mathrm{a}$ ). Compared with $1 \mathrm{H}$, the binding with $2 \mathrm{H}$ protonation state had a smaller binding free energy, implying that $\mathrm{Ca}^{2+}$ ions were relatively more easily chelated with $1 \mathrm{H}$ instead of $2 \mathrm{H}$ in a neutral condition. The compound $\mathrm{Ca}\left(\eta^{1}-3 \mathrm{H}\right)$ in acidic conditions had the smallest binding free energy $(-6.15 \mathrm{kcal} / \mathrm{mol})$. 
(a)

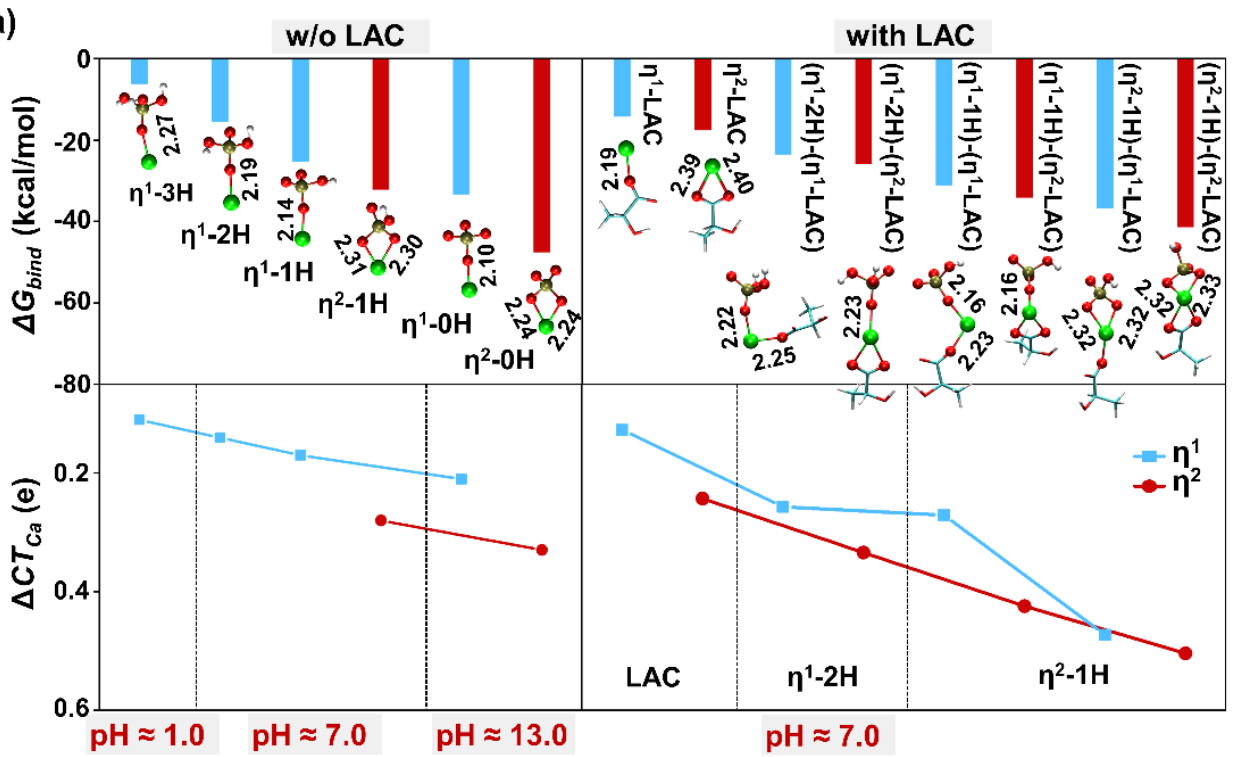

(b)

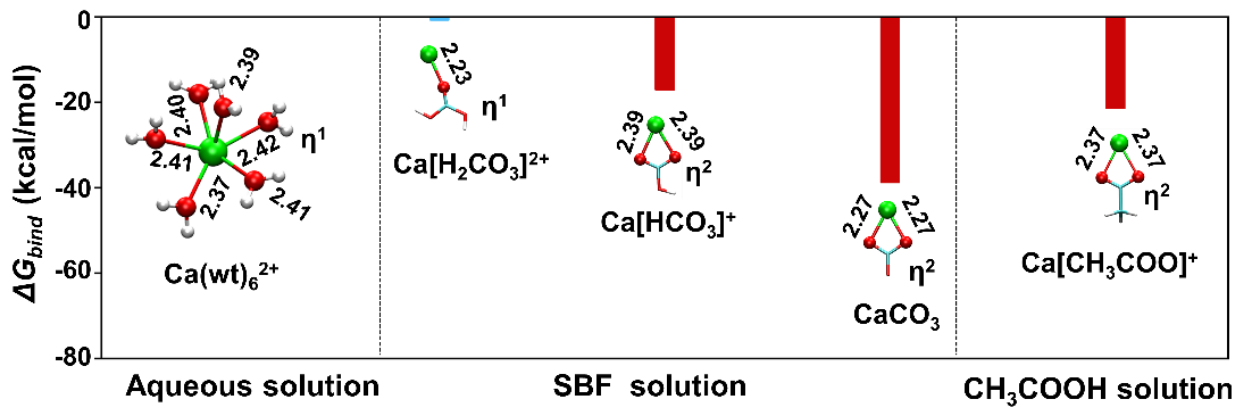

Figure 3. (a) The calculated binding free energies $-\Delta G_{\text {bind }}(\mathrm{kcal} / \mathrm{mol})$ of different compounds w/o and with LAC at the level of M062X/6-311+g(d,p) with PCM model, and the $C T$ extent described by charge difference between $\mathrm{Ca}^{2+}$ ion in $\mathrm{Ca}-\mathrm{O}$ binding compound and an isolated $\mathrm{Ca}^{2+}$ ion $\left(\Delta C T_{\mathrm{Ca}}\right)$ of $\mathrm{CaP}$ complex w/o and with the attached LAC; (b) the relative binding free energies between $\mathrm{Ca}^{2+}$ ion and solvent molecules with the binding energy of the 6-coordinated water complex taken as a reference. The units of distance are $\AA$. Color codes: $\mathrm{Ca}=$ green; $\mathrm{O}=\mathrm{red} ; \mathrm{P}=\tan ; \mathrm{C}=$ cyan; $\mathrm{H}=$ white.

Competitive interactions with LAC and solvent molecules. LAC could also coordinate with $\mathrm{Ca}^{2+}$ ions by $\eta^{1}$ and $\eta^{2}$ modes (Figure 3a), indicating that LAC may compete with phosphate species to chelate $\mathrm{Ca}^{2+}$ ions in solution. Since the elongation of LAC oligomer from $\mathrm{LAC}$ monomer to $\mathrm{LAC}_{8}$ did not change the binding strength too much (Table S1), we mainly analyzed the binding modes of LAC with the CaP clusters. 
As demonstrated in Figure 3a, the stronger binding strength of $\eta^{2}$ coordination mode than $\eta^{1}$ was closely related to the extent of $C T\left(\Delta C T_{C a}\right)$ between the interacting components. The electrostatic interaction was a dominating factor in tuning interfacial interactions with adding LAC or other additives and changing the $\mathrm{pH}$ conditions. In addition, the formation of the new $\mathrm{Ca}-\mathrm{O}$ bonds with adding LAC and other oxygencontaining solvent molecules would increase the $\mathrm{Ca}-\mathrm{O}$ distances in $\mathrm{CaP}$ cluster (Figure $3 \mathrm{a}$ ), indicating that the presence of LAC could weaken the binding ability of $\mathrm{Ca}^{2+}$ ions with phosphate species. Similarly, water molecules in aqueous solution, $\mathrm{H}_{2} \mathrm{CO}_{3}, \mathrm{HCO}_{3}{ }^{-}$ and $\mathrm{CO}_{3}{ }^{2-}$ ions in $\mathrm{SBF}$ solution and $\mathrm{CH}_{3} \mathrm{COO}^{-}$group in $\mathrm{CH}_{3} \mathrm{COOH}$ solution might compete with phosphate species to chelate $\mathrm{Ca}^{2+}$ ions with non-negligible relative binding strengths (Figure 3b). It should be mentioned that the both $\mathrm{LAC}$ and $\mathrm{CH}_{3} \mathrm{COO}^{-}$ could form double hydrogen bonding interactions with $2 \mathrm{H}$, which have binding energies of about -3.49 and $-5.85 \mathrm{kcal} / \mathrm{mol}$, respectively (Figure S1 and Figure S6). In summary, the existence of $\mathrm{LAC} \mathrm{CH}_{3} \mathrm{COO}^{-}, \mathrm{CO}_{3}{ }^{2-}$ ions may reduce the amount of 'free' and 'active' $\mathrm{Ca}^{2+}$ ions and phosphate species in both aqueous and SBF solutions, affecting the aggregation of $\mathrm{Ca}^{2+}$ ions and phosphate species.

Interfacial interaction on DCPD or HA surfaces. It is also meaningful to survey the interfacial interaction of LAC (or $\mathrm{CH}_{3} \mathrm{COOH}$ ) with DCPD (or HA) surface, which represents the large sized $\mathrm{CaP}$ systems and crystallization product after nucleation (Figure 4a). It has been demonstrated in our recent work that the coordination number of $\mathrm{Ca}^{2+}$ ion is one of the important features to govern the surface energy of HA nanoparticles with $\mathrm{Ca} / \mathrm{P}=1.67 .{ }^{51}$ Here, we also find the important role of coordination number of $\mathrm{Ca}^{2+}$ on surface (or in bulk), which is denoted as $\mathrm{N}_{\text {Ca-surface }}$ (or $\mathrm{N}_{\text {Ca-contact }}$ ), played in predicting the surface stability of DCPD and HA. Each $\mathrm{Ca}^{2+}$ ion of DCPD phase is surrounded by eight oxygen atoms from the surrounding four phosphate groups and two crystal water molecules (Figure $4 \mathrm{~b}$ ). For those eight-coordinated $\mathrm{Ca}^{2+}$ ions in DCPD, $\mathrm{N}_{\text {Ca-contact }}=8$, which is different from the two different sites, denoted as Ca1 $\left(\mathrm{N}_{\text {Ca-contact }}=9\right)$ and $\mathrm{Ca} 2\left(\mathrm{~N}_{\text {Ca-contact }}=7\right)$, respectively, in HA. Because DCPD is a calcium-deficient mineral, the number of its surface $\mathrm{Ca}$ atoms, $\mathrm{N}_{\mathrm{Ca} \text {-surface, }}$ is less than 
that of HA $(\mathrm{Ca} / \mathrm{P}=1.67)$. The $(020)$ facet is a characteristic surface for DCPD. As shown in Table S4, the resultant $\mathrm{HPO}_{4}$-exposed (020) surface of DCPD has smaller surface energy $E_{\text {surf }}\left(0.49 \mathrm{~J} / \mathrm{m}^{2}\right)$ than those of HA surfaces (e.g., (001) surface energy of $\mathrm{HA}$ is $1.08 \mathrm{~J} / \mathrm{m}^{2}$ ). Thus, we focused on the $\mathrm{HPO}_{4}$-exposed DCPD (020) in this work.

The change of $\mathrm{pH}$ values could lead to the difference in $\mathrm{Ca} / \mathrm{P}$ ratios. ${ }^{71}$ Being stimulated by such $\mathrm{pH}$-dependent phenomena, we attempt to tune the $\mathrm{Ca} / \mathrm{P}$ ratios in our simulation models by changing the number of hydroxyl groups in HA unit cell, as shown in Figure S7 and Table S25. For tuning the Ca/P ratios in the DCPD-like phase, the additional $\mathrm{Cl}^{-}$ions are added to keep charge neutralization when changing the number of $\mathrm{HPO}_{4}{ }^{2-}$ and $\mathrm{Ca}^{2+}$ ions in unit cell (Table S25). The simulated XRD patterns for the different $\mathrm{Ca} / \mathrm{P}$ ratios (Figure $4 \mathrm{~b}$ ) can be taken as the combination of the standard diffractograms of DCPD (JCPDS\#09-0077, Ca/P = 1.00), OCP (JCPDS\#26-1056, Ca/P = 1.33), and HA (JCPDS\#09-0432, $\mathrm{Ca} / \mathrm{P}=1.67)$.

The coordination modes and capabilities of surface $\mathrm{Ca}$ ions are also changed with the variation of $\mathrm{Ca} / \mathrm{P}$ ratios (Figure $4 \mathrm{a}$ and Table S5). For the LAC adsorbed on (020) DCPD surface, the $\mathrm{Ca} / \mathrm{P}$ of 2.00 has the largest $E_{\text {bind }}$ value $(-71.25 \mathrm{kcal} / \mathrm{mol})$, consistent with the smallest $\mathrm{N}_{\mathrm{Ca} \text {-surface }}$ value relative to the other $\mathrm{Ca} / \mathrm{P}$ ratios. In such high $\mathrm{Ca} / \mathrm{P}$ ratio, the surface $\mathrm{Ca}^{2+}$ ions seem to be still 'active' for binding with LAC additive. The strongest interfacial interaction between LAC and HA surfaces was also found at $\mathrm{Ca} / \mathrm{P}$ $=2.00$ (S6 of supporting information). As shown in Figure S6, the atomic charges on the two carboxyl oxygen atoms of LAC had similar values (-0.58 and $-0.56 e)$ to that of the oxygen atom $(-0.59 e)$ in a water molecule, suggesting that LAC might occupy the position of crystal water molecule to chelate with $\mathrm{Ca}^{2+}$ ions close to the surface of DCPD phase. It can be thus expected that the change of $\mathrm{pH}$ values and the addition of LAC could tune the surface stability and morphology of DCDP sample, which will be demonstrated in the experiments in subsection 3.5. 
(a)

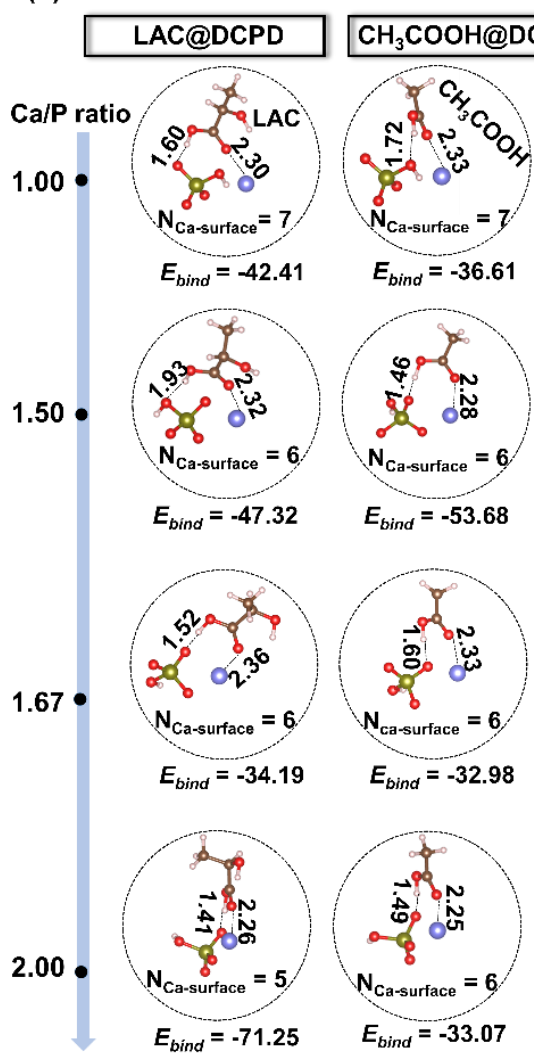

(b)

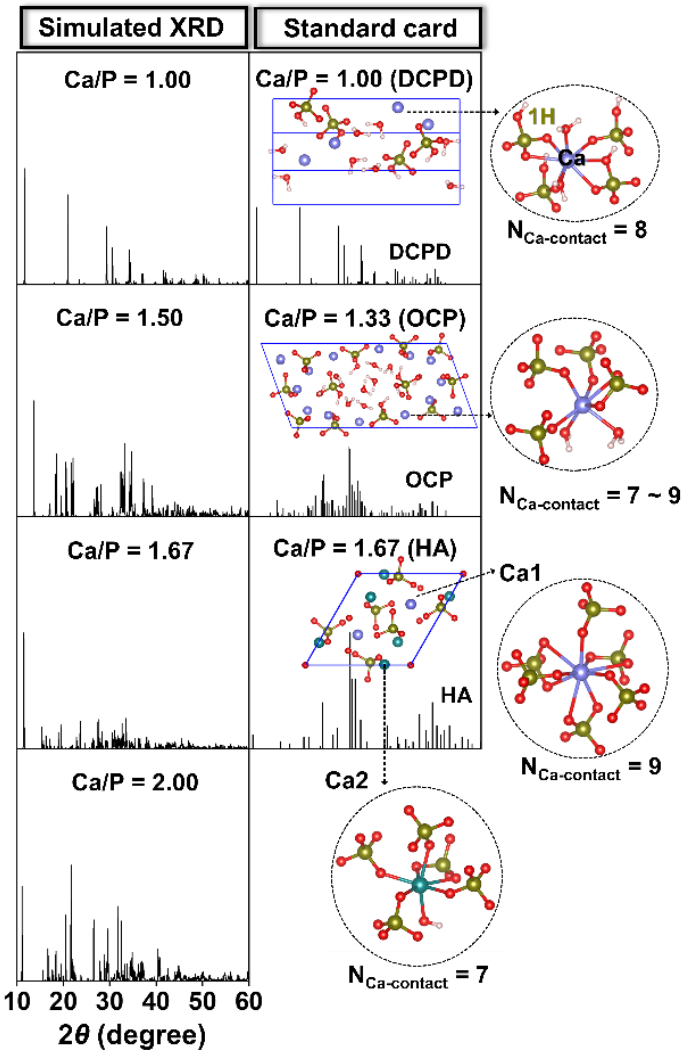

Figure 4. (a) The interfacial binding modes, binding energies ( $E_{\text {bind }}$, in units of kcal $\left./ \mathrm{mol}\right)$ of LAC and $\mathrm{CH}_{3} \mathrm{COOH}$ with the (020) surface of DCPD, (b) simulated XRD patterns of DCPD-based models with different $\mathrm{Ca} / \mathrm{P}$ ratios, in comparison with standard cards of DCPD (JCPDS\#09-0077), OCP (JCPDS\#26-1056), and HA (JCPDS\#09-0432). XRD simulation calculations are performed using the Powder Diffraction function in Materials Studio ${ }^{72} /$ Reflex module. The coordination numbers of $\mathrm{Ca}^{2+}$ on surface and in bulk are denoted as $\mathrm{N}_{\text {Ca-surface }}$ and $\mathrm{N}_{\text {Ca-contact, }}$ respectively. Color codes: $\mathrm{Ca}, \mathrm{Ca} 1=$ purple; $\mathrm{Ca} 2=$ cyan $; \mathrm{O}=$ red; $\mathrm{P}=$ golden $; \mathrm{C}=\tan ; \mathrm{H}=$ white.

\subsection{The pH dependent coordination modes in pre-nucleation clusters}

AIMD simulations with PBE functional and GTH-DZVP basis set were further carried out to provide more detailed information on the intermolecular interactions between phosphate species and $\mathrm{Ca}^{2+}$ ions in the early aggregation stage. For the dominated $2 \mathrm{H}$ and $3 \mathrm{H}$ species in acidic conditions, most of the coordination modes of $\mathrm{Ca}^{2+}$ were in $\eta^{1}$, as displayed by a single sharp peak in the radial distribution function 
(RDF) of Ca-P distance (Figure 5a). To the other end, the $\mathrm{Ca}^{2+}$ coordinated with the deprotonated species of $0 \mathrm{H}$ and $1 \mathrm{H}$ in alkaline conditions in both $\eta^{1}$ and $\eta^{2}$ modes, corresponding to the two overlapping peaks at $3.1 \AA$ and $3.7 \AA$ in RDF, which was also in line with our DFT optimizations of various CaP clusters in Figure 3a. The simulation of $\mathrm{pH} \approx 7.4$ involved the two coexisting $2 \mathrm{H}$ and $1 \mathrm{H}$ species, which had different binding modes toward $\mathrm{Ca}^{2+}$ ions, i.e., $2 \mathrm{H}$ was bound in $\eta^{1}$, but $1 \mathrm{H}$ was chelated in both $\eta^{1}$ and $\eta^{2}$ modes. $\mathrm{Ca}^{2+}$ ions were mainly chelated with non-hydroxyl oxygen atoms of phosphate species based on the SDF (Figure 5a). A nearby water molecule pulled one hydrogen atom of the $3 \mathrm{H}$ through the hydrogen bonding $(\mathrm{pH} \approx 1.0)$. Such a hydrated proton was stabilized by forming a concerted hydrogen bonding chain in the surrounding water solvent molecules. The number of non-hydroxyl oxygen atoms of phosphate species increased as the $\mathrm{pH}$ value increases, leading to the formation of the cage-like $\mathrm{CaP}$ prenucleation cluster. Each $\mathrm{Ca}^{2+}$ ion sat at the cage vertex to bridge 2 4 oxygen atoms of phosphates with significant binding energies. The addition of LAC introduced the competitive coordination interactions with $\mathrm{Ca}^{2+}$ ions, decreasing the contact chance of phosphates with 'free' $\mathrm{Ca}^{2+}$ ions and destroying the cage structure of the $\mathrm{CaP}$ cluster (Figure 5b).

The AIMD simulations are not affordable for the more complicated systems with thousands of atoms. The classical MD simulations based on GAFF2 force field were then carried out to study the influence of LAC oligomers in a much larger space and time scale (S7 of supporting information: Figure S8 and Figure S9) with and without LAC (or $\mathrm{LAC}_{8}$ ), as shown in Figure S8. To gain insight into calcium phosphate precipitation and biological mineralization in the physiological environment, the SBF solutions with ion concentrations and $\mathrm{pH}$ value similar to the human blood plasma were also introduced in our MD simulations. The coordination modes of phosphate species and $\mathrm{Ca}^{2+}$ ions obtained by GAFF2 based MD simulations (Figure S8, Figure S9) were similar to those revealed from the above-mentioned AIMD simulations, validating the adopted force field parameters. 
The longer oligomer, $\mathrm{LAC}_{8}$, is slightly diffferent from the $\mathrm{LAC}$ monomer. $\mathrm{LAC}_{8}$ took a zigzag conformation and preferred to chelate with $\mathrm{Ca}^{2+}$ ions through its terminal carboxyl group, and the other oxygen-containing functional groups could form hydrogen bonds with nearby water molecules (Figure S8). The cage-like CaP cluster was difficult to aggregate in the vicinity of $\mathrm{LAC}_{8}$. To make comparison with SBF solution, the neutral aqueous solution with $\mathrm{pH} \approx 7.4$ were also studied (Figure S9). The existence of various ion compositions in SBF solution brought little difference in coordination modes of $\mathrm{CaP}$ from those in aqueous solution. The present GAFF2 based MD simulations on an aqueous solution of $\mathrm{Ca}^{2+}$ ions and $0 \mathrm{H}$ species demonstrated the $\eta^{1}$ and $\eta^{2}$ coordination modes by the two peaks at 3.2 and $3.8 \AA$ in RDF, similar to the previous MD simulations based on the INTERFACE force field ${ }^{73}$.

(a) w/o LAC $\left(\left[\mathrm{Ca}^{2+}\right]=1.21 \mathrm{~mol} \cdot \mathrm{dm}^{-3}\right)$

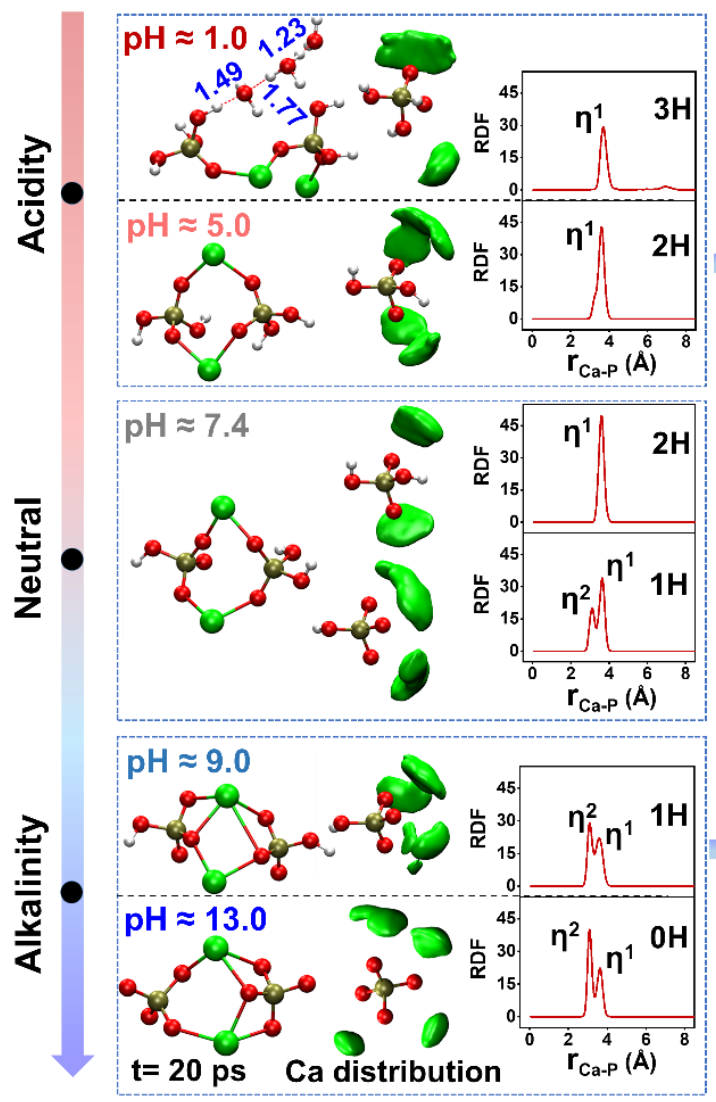

(b) with LAC $\left(\left[\mathrm{Ca}^{2+}\right]=1.21 \mathrm{~mol} \cdot \mathrm{dm}^{-3}\right)$
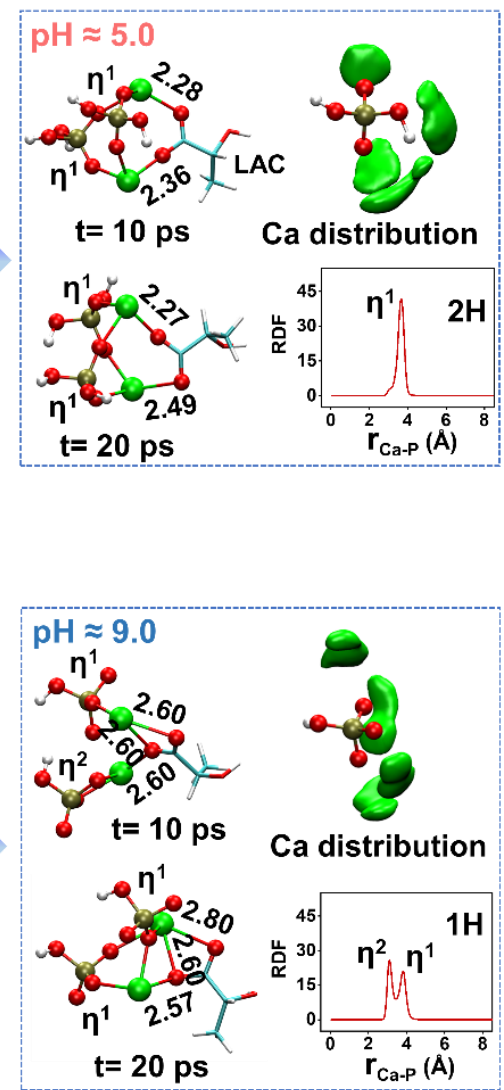

Figure 5. The selected AIMD snapshots, SDF (isosurfaces for Ca atoms are represented in green, and isovalues of Ca atoms are set to be 50 particles $/ \mathrm{nm}^{3}$ ), and RDF of studied 
systems (a) w/o LAC and (b) with LAC, respectively. Only the adjacent water molecules with $2.0 \AA$ are shown in the sampled snapshots at 20 ps for clarity. Color codes: $\mathrm{Ca}=$ green $; \mathrm{O}=$ red; $\mathrm{P}=\tan ; \mathrm{C}=$ cyan $; \mathrm{H}=$ white.

\subsection{Aggregation of post-nucleation clusters in aqueous and SBF solutions}

Influences of pH conditions and LAC oligomers. As mentioned before, the $\mathrm{CaP}$ system with high $\mathrm{Ca} / \mathrm{P}$ ratio of 2.00 has some 'active' surface $\mathrm{Ca}^{2+}$ ions for binding with phosphates and additives at interface. So, we lay emphasis on the MD simulation models with $\mathrm{pH} \approx 7.4$ and $\mathrm{Ca} / \mathrm{P}=2.00$, in which $1 \mathrm{H}$ and $2 \mathrm{H}$ ions were randomly distributed in the SBF solutions (Figure 6a, Figure S10). With the evolution of MD simulation, the initial small-sized and loosely bound $\mathrm{CaP}$ clusters attracted each other and aggregated into the larger clusters consisting of about $10 \mathrm{Ca}^{2+}$ ions at $500 \mathrm{~ns}$ (Figure S10). By the end of the $500 \mathrm{~ns}$ MD simulation, about $58 \%$ of $\mathrm{Ca}^{2+}$ ions in those $\mathrm{CaP}$ clusters were coordinated by phosphate species, and some $\mathrm{Ca}^{2+}$ ions were found at the upmost surface of the formed clusters. LAC monomer could chelate with $\mathrm{Ca}^{2+}$ ions during the entire simulation time (Figure $6 \mathrm{~b}$ ). However, the longer oligomer $\mathrm{LAC}_{8}$ was mainly keeping free (Figure 6c) because of its weaker binding ability to $\mathrm{Ca}^{2+}$ ions than the LAC monomer. Some other oxygen-containing units, such as $\mathrm{LAC}, \mathrm{HCO}_{3}{ }^{-}$ions of SBF solution both competed with phosphate species to chelate $\mathrm{Ca}^{2+}$ ions through $\mathrm{Ca}-\mathrm{O}$ ionic bonding (Figure 6b). We selected two typical clusters to illustrate the binding modes of oxygen-containing groups (phosphate group and LAC) with $\mathrm{Ca}^{2+}$ ions, as shown in the inset of Figure 6. In cluster 1, two bridging $\mathrm{Ca}^{2+}$ ions were in distorted tetrahedral and trihedral coordinations formed by the surrounding LAC molecules. The two $\mathrm{Ca}^{2+}$ ions in cluster 2 bound with two LAC monomers and $2 \mathrm{H}$ ion through trihedral and bilateral coordinations, while all of the other three $\mathrm{Ca}^{2+}$ ions were tetrahedrally coordinated with the surrounding $1 \mathrm{H}$ species to form a compact $\mathrm{CaP}$ cage. At $\mathrm{pH} \approx 5.0$, there were still several free $2 \mathrm{H}$ species that did not coordinate with $\mathrm{Ca}^{2+}$ ions ( $\mathrm{S} 8$ of supporting information: Figure $\mathrm{S} 11$ ), because $2 \mathrm{H}$ has weaker coordination strength than that with $1 \mathrm{H}$ in $\mathrm{pH} \approx 7.4$ solution (Figure $\mathrm{S} 12$ ). MD simulations of the basic conditions 
with $\mathrm{pH} \approx 9.0$ (Figure $\mathrm{S} 13$ ) and $\mathrm{pH} \approx 13.0$ (Figure S14) demonstrated similar aggregation behaviors of $\mathrm{CaP}$ clusters to the case of $\mathrm{pH} \approx 7.4$. But in the acid solution with $\mathrm{pH} \approx 1.0$, only small $\mathrm{CaP}$ clusters containing $2-3 \mathrm{Ca}^{2+}$ ions were formed even at $500 \mathrm{~ns}$ trajectory (Figure S15), because of the weakest $\mathrm{Ca}^{2+}$ binding strength with $3 \mathrm{H}$ species than the other phosphates. Nearly $92 \% \mathrm{Ca}^{2+}$ ions and $83 \% 3 \mathrm{H}$ phosphates stayed in the free state with addition of LAC (Figure S15). The sophisticated free energy calculations on basis of the $5 \mu$ s M simulations have demonstrated that the thermodynamically favored pathway of nucleation process started from the ion pair in solution. ${ }^{24}$ It was also displayed that there were still some free $\mathrm{Ca}^{2+}$ ions by the end of the long-time $\mathrm{MD}$ simulation in water with $\mathrm{Ca} / \mathrm{P}$ ratio of 2.00 , which was consistent with our simulation results (Figure S24).

In order to evaluate the whole evolution process of clusters aggregation with a qualitative descriptor, we counted the number of phosphate species and $\mathrm{Ca}^{2+}$ ions in each cluster. In the first step, we calculated the radial distribution functions (RDF) of Ca-P (phosphate species) (Figure S16), and then the cutoff distance (R) was set based on the local minimum of the corresponding RDF. Accordingly, the number of phosphate species or $\mathrm{Ca}^{2+}$ ions in each cluster was counted within the cutoff radius $\mathrm{R}$. In our code, we took one of the $\mathrm{Ca}^{2+}$ or phosphates as the center, and searched all the target species (Figure S17). Here, we selected the largest $\mathrm{CaP}$ cluster and $\mathrm{N}_{\text {Ca-contact }}$ (the number of $\mathrm{Ca}^{2+}$ ions around phosphate species within the cutoff radius) to evaluate the whole evolution process of CaP clusters, with the results shown in Figures S18-S24. The chelation of LAC with $\mathrm{Ca}^{2+}$ in $\eta^{1}$ and $\eta^{2}$ modes prevented $\mathrm{Ca}^{2+}$ ions from binding with phosphate species, yielding a small size of largest CaP cluster and small value of $\mathrm{N}_{\text {Ca-contact }}$ value in the neutral and alkaline conditions with different $\mathrm{Ca} / \mathrm{P}$ ratios (Figures S18, S20, S23). In contrast, the presence of $\mathrm{LAC}_{8}$ had little effect on the size of the largest $\mathrm{CaP}$ cluster and the number of $\mathrm{N}_{\mathrm{Ca} \text {-contact }}$ because of its weaker binding ability to $\mathrm{Ca}^{2+}$ ions in all $\mathrm{pH}$ conditions. In fact, LAC polymer with the much longer chain length is insoluble in CaP solutions, as observed in our experiments. 
(a) w/o additives $\left(\left[\mathrm{Ca}^{2+}\right] \approx 0.32 \mathrm{~mol} \cdot \mathrm{dm}^{-3}\right)$

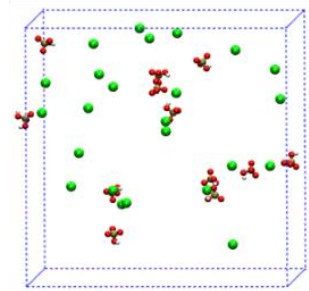

(b) with LAC

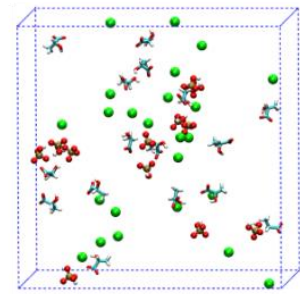

(c) with $\mathrm{LAC}_{8}$

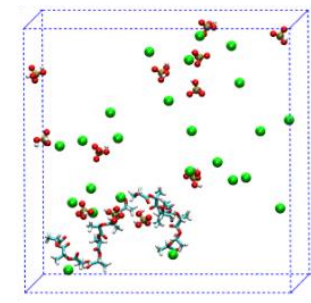

Time
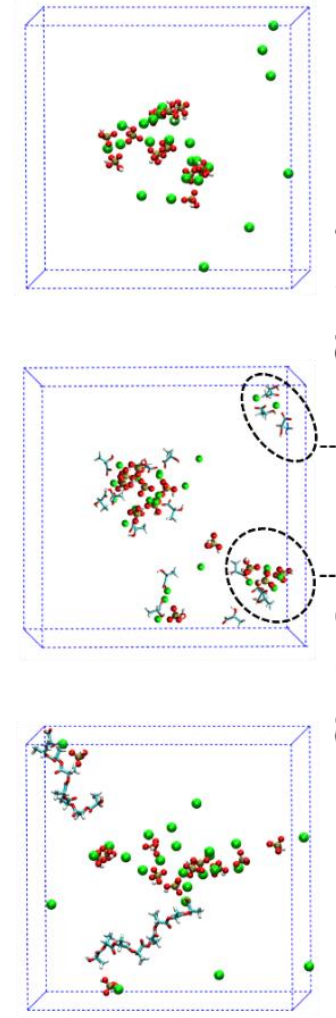

$500 \mathrm{~ns}$
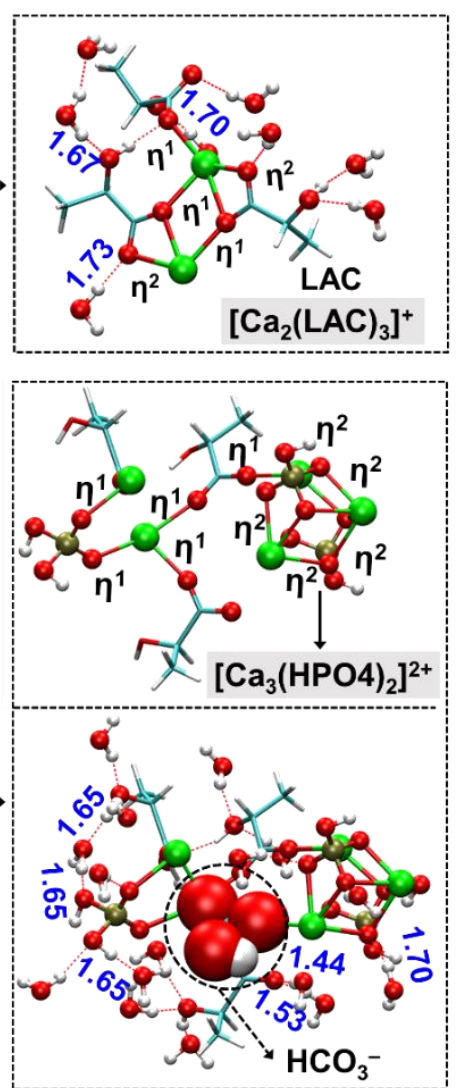

Figure 6. MD snapshots with the explicit illustration of $\mathrm{Ca}^{2+}$ ions, $1 \mathrm{H}, 2 \mathrm{H}$ ions, LAC and $\mathrm{LAC}_{8}$ at $0 \mathrm{~ns}$ and $500 \mathrm{~ns}$ of $\mathrm{CaP}$ systems $(\mathrm{Ca} / \mathrm{P}=2.00, \mathrm{pH} \approx 7.4)$ in SBF solutions (a) w/o additives, (b) with LAC and (c) with $\mathrm{LAC}_{8}$, respectively. Water molecules are omitted for clarity. $\mathrm{Ca}^{2+}$ ions are shown as green (VDW), $1 \mathrm{H}$ and $2 \mathrm{H}$ ions as $\mathrm{CPK}$ and VDW, LAC and $\mathrm{LAC}_{8}$ as Licorice. Color codes: $\mathrm{Ca}=$ green; $\mathrm{O}=\mathrm{red} ; \mathrm{P}=\tan ; \mathrm{C}=$ cyan; $\mathrm{H}=$ white

Electrostatic potential surfaces (EPS) of CaP clusters. The uneven charge distribution at the surface of the $\mathrm{CaP}$ cluster leads to significant electrostatic interactions, which would play an important role in the binding affinities toward proteins and nucleation processes. ${ }^{51,74}$ For example, the nano-sized CaP clusters had been found to have binding specificity toward AP2 protein through electrostatic interactions with the charged residues. ${ }^{74} \mathrm{We}$ are now curious about the change of electrostatic potential distribution of the $\mathrm{CaP}$ aggregates upon the complexation with LAC oligomers. The 
exposed groups were dominated by the positively charged $\mathrm{Ca}^{2+}$ ions (blue color) on the cluster surfaces in both acidic and alkaline conditions (Figure 7a). Those exposed $\mathrm{Ca}^{2+}$ ions are still 'active' and could be coordinated with nearby water molecules to stabilize the clusters. The addition of LAC led to the charge redistribution to allow negatively charged phosphate species (red color) to be exposed at the outmost surface of the CaP cluster. However, the relatively weaker electrostatic interaction between $\mathrm{LAC}_{8}$ and $\mathrm{Ca}^{2+}$ ions did not result in such a large change in the EPS of the CaP cluster. The distribution of postively and negatively charged groups at the CaP cluster surface could be correlated with the zeta potential experiments in the following subsection.

When the $\left[\mathrm{Ca}^{2+}\right]$ is relatively high, the exposed $\mathrm{Ca}^{2+}$ ions on the $\mathrm{CaP}$ cluster surface will push the free $\mathrm{Ca}^{2+}$ ions due to electrostatic repulsion, slowing down the formation of $\mathrm{CaP}$ precipitation in the early nucleation process. The addition of LAC led to the formation of the phosphate-exposed clusters with negative surface charge distribution, which could continue to chelate with $\mathrm{Ca}^{2+}$ ions through electrostatic attraction and possibly induce the large sized precipitation. Moreover, our MD simulations demonstrated the formation of the Posner-like clusters, such as Ca-deficient complex $\left[\mathrm{Ca} 7\left(\mathrm{PO}_{4}\right)_{6}\right]^{4-}$ and Posner's cluster $\mathrm{Ca} 9\left(\mathrm{PO}_{4}\right)_{6}($ Figure $7 \mathrm{a})$ with different $\mathrm{Ca} / \mathrm{P}$ ratios. The Ponser's cluster ${ }^{75}$ was usually considered to be crucial in the nucleation process of $\mathrm{CaP}$ in solution. Those small sized CaP clusters could also be assembled in the form of multiple Posner's clusters such as $\mathrm{Ca}_{108}\left(\mathrm{PO}_{4}\right)_{72}(\mathrm{OH})_{10}$ with $\mathrm{Ca} / \mathrm{P}=1.50$ on the collagen surface. $^{73}$

The exsitence of those Ca-deficient post-nucleation clusters gave us a hint to obtain DCPD precipitations with tunable surface stability under different $\mathrm{pH}$ conditions. As expected, the Ca-exposed (020) DCPD surface had the largest value of surface energy, $E_{\text {surf }}$, with smallest coordination number of $\mathrm{Ca}^{2+}$ ions on surface $\left(\mathrm{N}_{\mathrm{Ca} \text {-surface}}\right)$. The Ca-exposed surface would be transferred into the more stable $\mathrm{HPO}_{4}$-exposed surface, whose surface $\mathrm{Ca}^{2+}$ ions are inactive and capped with phosphates. As shown in Figure $7 \mathrm{~b}$ and Table S4, the surface energy of $\mathrm{HPO}_{4}$-exposed (020) surface is even lower than those of different surfaces of $\mathrm{HA}(\mathrm{Ca} / \mathrm{P}=1.67)$, in agreement with the recently reported 
correlation between the coordination number of surface $\mathrm{Ca}^{2+}$ ions and the surface energy of HA nanoparticles. ${ }^{51}$
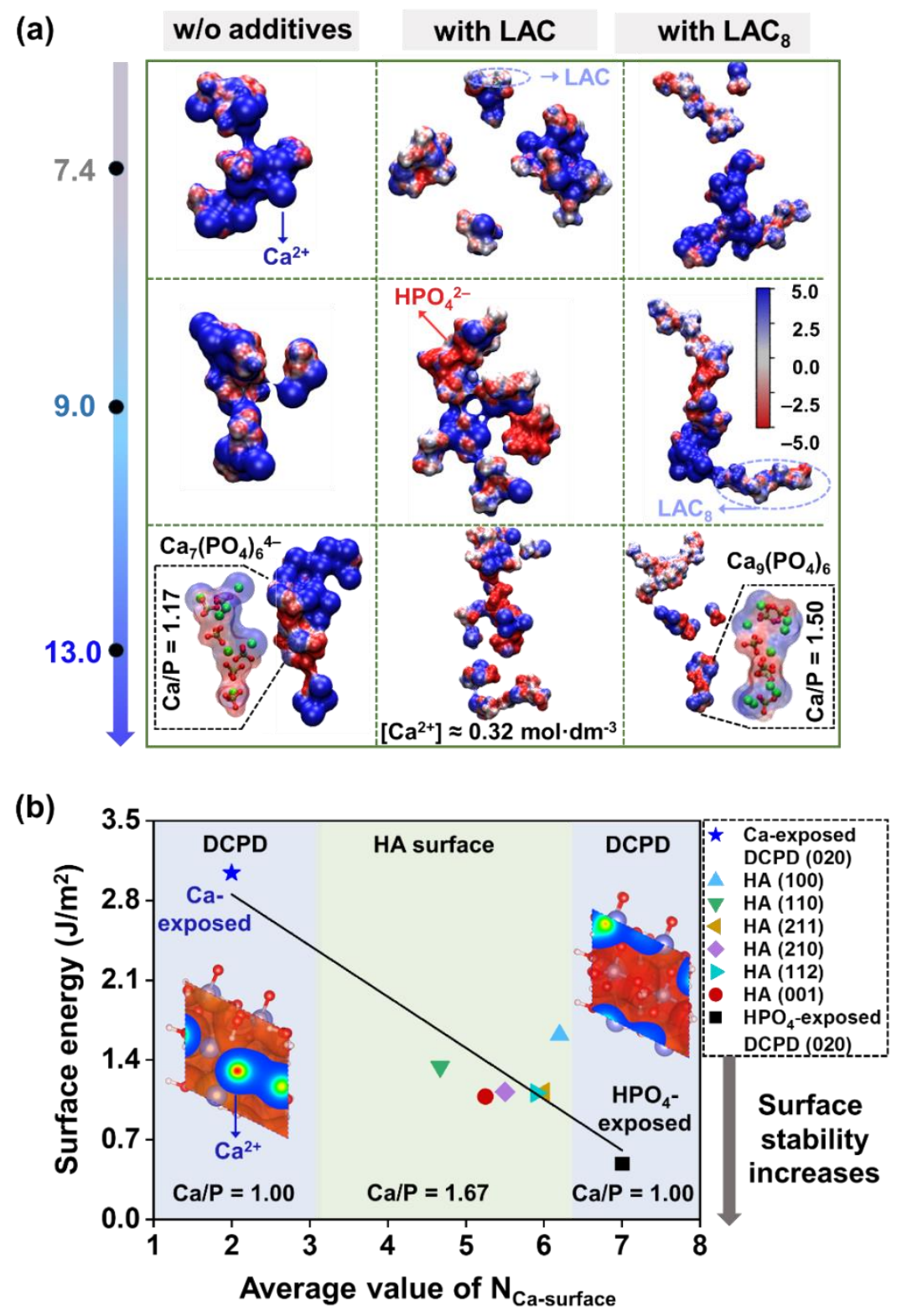

Figure 7. (a) Electrostatic potential surface maps of $\mathrm{CaP}$ clusters w/o and with $\mathrm{LAC}_{\mathrm{n}}$ oligomers $(\mathrm{n}=1,8)$ under different $\mathrm{pH}$ values $(\mathrm{Ca} / \mathrm{P}=2.00)$ sampled at $500 \mathrm{~ns}$ of $\mathrm{MD}$ simulation, (b) Correlation between the coordination number of surface $\mathrm{Ca}^{2+}$ ions and the surface energy of DCPD and HA surfaces. Top view of the electrostatic potentials of the Ca- and $\mathrm{HPO}_{4}$-exposed (020) DCPD surface with the isosurface value setting as $0.01 e / \AA^{3}$. The electrostatic potentials for CaP clusters are calculated with APBS 
software, and the units for electrostatic potential are $\mathrm{k}_{\mathrm{B}} \mathrm{T} / e$. Color codes: $\mathrm{Ca}=$ green; $\mathrm{O}$ $=$ red; $\mathrm{P}=\tan$.

\subsection{High-throughput experimentations with a combination of different factors}

The above mentioned theoretical results could give a general picture of nucleation of CaP system, depicted in Figure 8a. In a dilute solution with low $\left[\mathrm{Ca}^{2+}\right]$ concentration, the aggregation of the free $\mathrm{Ca}^{2+}$ ions and phosphate species is controlled by their binding strength under different $\mathrm{pH}$ values. The LAC would give significant impacts through the competitive coordination with the free $\mathrm{Ca}^{2+}$ ions and stabilization of the Caexposed $\mathrm{CaP}$ cluster, inhibiting the further aggregation and nucleation in dilute solution. As the $\left[\mathrm{Ca}^{2+}\right]$ concentration increases, $\mathrm{Ca}^{2+}$ ions and phosphate species attract each other and aggregate into the $\mathrm{CaP}$ clusters. Eventually, with the increasing coordination number of surface $\mathrm{Ca}^{2+}$ ions, the post-nucleation clusters grow into DCPD precipitation, which has the highest nucleation rates among Ca-P phases ${ }^{76}$ and the lowest surface energy (Figure 7). In this case, the addition of small amount of LAC could further stabilize the DCPD precipitation by interacting with the exposed surface $\mathrm{Ca}^{2+}$ ions.

To test those speculations, we design the experiments by changing different factors, such as $\left[\mathrm{Ca}^{2+}\right]$ concentration, $\mathrm{Ca} / \mathrm{P}$ ratio, and additive ( $\mathrm{LAC}$ and $\mathrm{CH}_{3} \mathrm{COOH}$ ), solvation environment (aqueous, SBF, and DPBS) (Figure 8b). Our experiments are classified into four sets according to the different $\left[\mathrm{Ca}^{2+}\right]$ concentrations, called low, medium, high, and very high in short, as introduced as follows. 
(a)

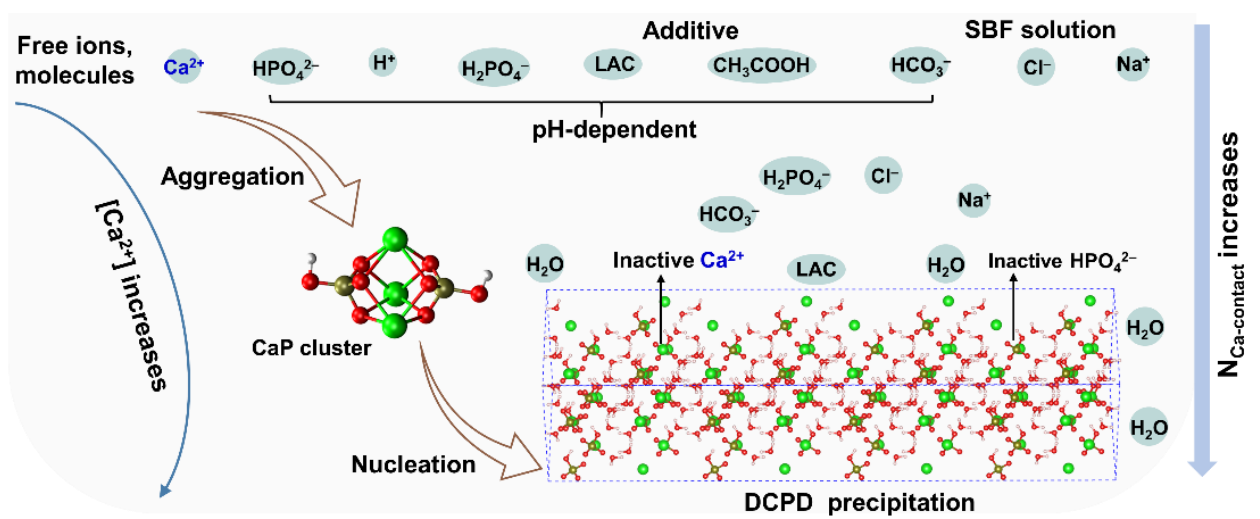

(b)

DCPD precipitation

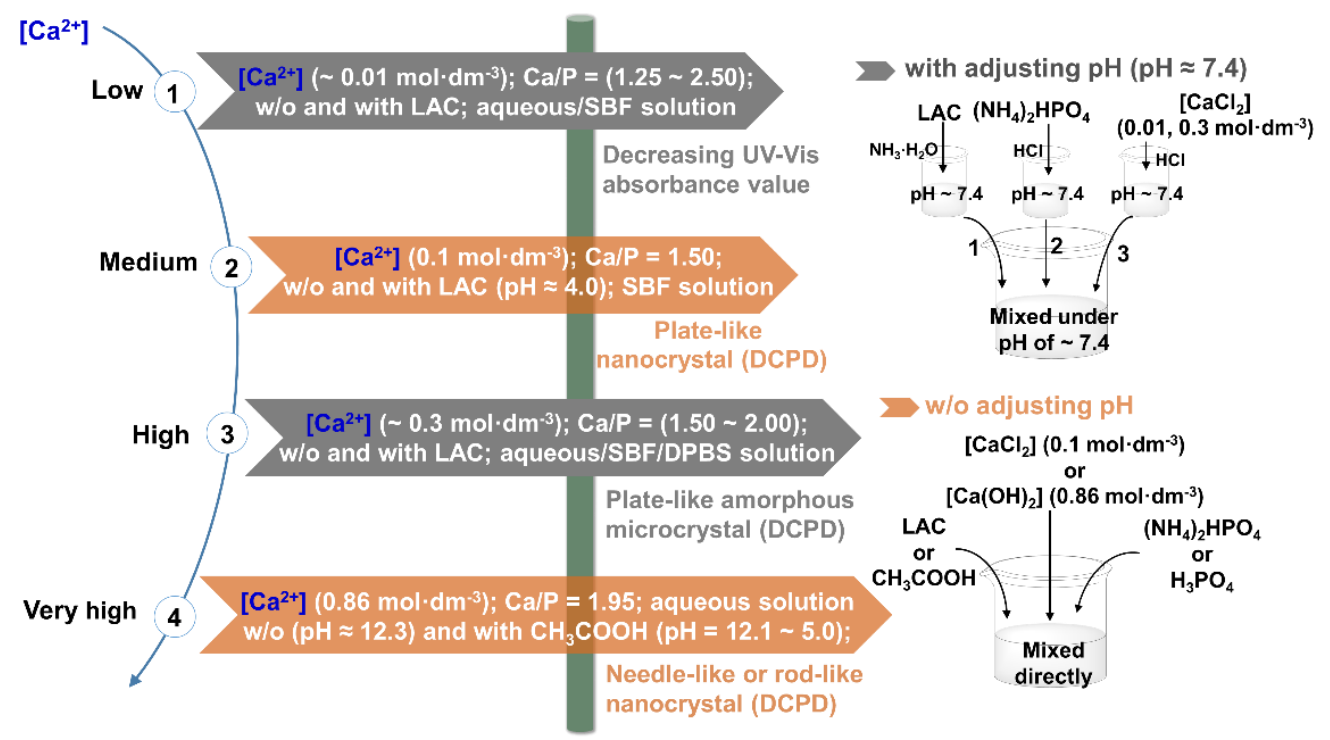

Figure 8. Schematic illustrations for (a) nucleation process of $\mathrm{CaP}$ in aqueous or SBF solution as the $\left[\mathrm{Ca}^{2+}\right]$ concentration increases, (b) four experimental conditions classified by different $\left[\mathrm{Ca}^{2+}\right]$ concentrations, $\mathrm{Ca} / \mathrm{P}$ ratio, and additive (LAC and $\mathrm{CH}_{3} \mathrm{COOH}$ ) in acidic solution (w/o adjusting $\mathrm{pH}$ and with additive) and neutral solution (with initial $\mathrm{pH}$ adjusting to 7.4). Color codes: $\mathrm{Ca}=$ green; $\mathrm{O}=$ red; $\mathrm{P}=\tan ; \mathrm{H}=$ white.

Low $\left[\mathrm{Ca}^{2+}\right]$ concentration. In order to further explore the influence of the different factors on the nucleation process in dilute solutions $\left(\left[\mathrm{Ca}^{2+}\right] \approx 0.01\right.$ and $0.005 \mathrm{~mol} \cdot \mathrm{dm}^{-}$ ${ }^{3}$ ), the HTE technique was applied to synthesize various CaP samples including 120 experimental groups (Figure 2). The UV-Vis absorbance values at $450 \mathrm{~nm}$ were then used to detect the amount of the formed precipitation in dilute solutions. Three parallel experiments were carried out to give the error bar of the observed absorbance values. 
We fixed the concentration of phosphate salt, and then determined the $\mathrm{Ca}^{2+}$ ion concentration based on the ratio of $\mathrm{Ca} / \mathrm{P}$. For example, if the phosphate salt concentration was $0.0067 \cdot \mathrm{dm}^{-3}$, the $\mathrm{Ca}^{2+}$ ion concentration was $0.01 \cdot \mathrm{dm}^{-3}$ when the $\mathrm{Ca} / \mathrm{P}$ ratio of 1.50 in aqueous solution. Under SBF solution, the $\mathrm{Ca}^{2+}$ ion concentration to be added was equal to the difference between $\mathrm{Ca}^{2+}$ ion concentration based on the $\mathrm{Ca} / \mathrm{P}$ ratio and $\mathrm{Ca}^{2+}$ ion concentration in $\mathrm{SBF}$ solution.

As shown in Figure 9, the UV-Vis absorbance values decreased with addition of LAC in both SBF and aqeuous solutions, indicating that the presence of LAC (with $[\mathrm{LAC}]=1.14 \mathrm{~mol} \cdot \mathrm{dm}^{-3}$, much larger than $\left.\left[\mathrm{Ca}^{2+}\right]\right)$ was not conducive to the formation of $\mathrm{CaP}$ precipitation. But when the $\mathrm{Ca} / \mathrm{P}$ ratio was greater than 2.00 , the presence of LAC had relatively smaller effect on the amount of precipitation. If the $\left[\mathrm{Ca}^{2+}\right]$ concentration was too low (i.e., $\left[\mathrm{Ca}^{2+}\right] \approx 0.005 \mathrm{~mol} \cdot \mathrm{dm}^{-3}$ ), the UV-Vis absorbance of $\mathrm{CaP}$ aqueous solution even vanished with the presence of LAC. This can be rationalized by our simulation results that the chelatation of $\mathrm{LAC}$ with $\mathrm{Ca}^{2+}$ ions reduced the number of free calcium ions for binding to phosphate groups at the early stage of the nucleation process.

Medium $\left[\mathrm{Ca}^{2+}\right]$ concentraion. It was also interesting to study the role of LAC in nucleation process by increasing the $\left[\mathrm{Ca}^{2+}\right]$ concentration to $0.1 \mathrm{~mol} \cdot \mathrm{dm}^{-3}$ (S5 of supporting information: Figure S5), so that the prepared samples were large enough to get their XRD patterns (Figure 10a, S9 of supporting information: Figure S25). The characteristic peaks of (020), (021), (041) without and with the addition of LAC were in good agreement with the standard XRD pattern for DCPD (JCPDS\#09-0077). It could be seen that the intensities of characteristic peaks such as (020), (021), (041) fluctuated with the increase of the stirring time (Figure 10b), which indicated that the nucleation of $\mathrm{CaP}$ was a dynamic process in solution. As revealed in Figure S25c, the peaks at about $25.90^{\circ}$ and $31.86^{\circ}$ with the prepared samples at $24 \mathrm{~h}$ were consistent with (002) and (211) reflection in the standard card (JCPDS\#09-0432), suggesting that the prepared samples were HA. It meant that DCPD could act as an intermediate phase 
during the formation of HA. The facial phase transformation was also observed in experiments of adding acidic amino acids to reduce the interfacial energy barrier between DCPD and HA. ${ }^{18}$ The HA was produced by the addition of DCPD seeds to the react solution through mixing calcium chloride and potassium dihydrogen phosphate with sodium chloride at $25^{\circ} \mathrm{C}(\mathrm{pH} \approx 8.45) .{ }^{18}$ The metastable DCPD could also be converted to $\mathrm{HA}$ in appropriate conditions, such as on coated $\mathrm{Mg}$ alloy samples after alkaline treatment ${ }^{77}$, adding the citrate ${ }^{19}$, and using $\mathrm{NaOH}$ solutions ${ }^{16}$.

(a) SBF solution
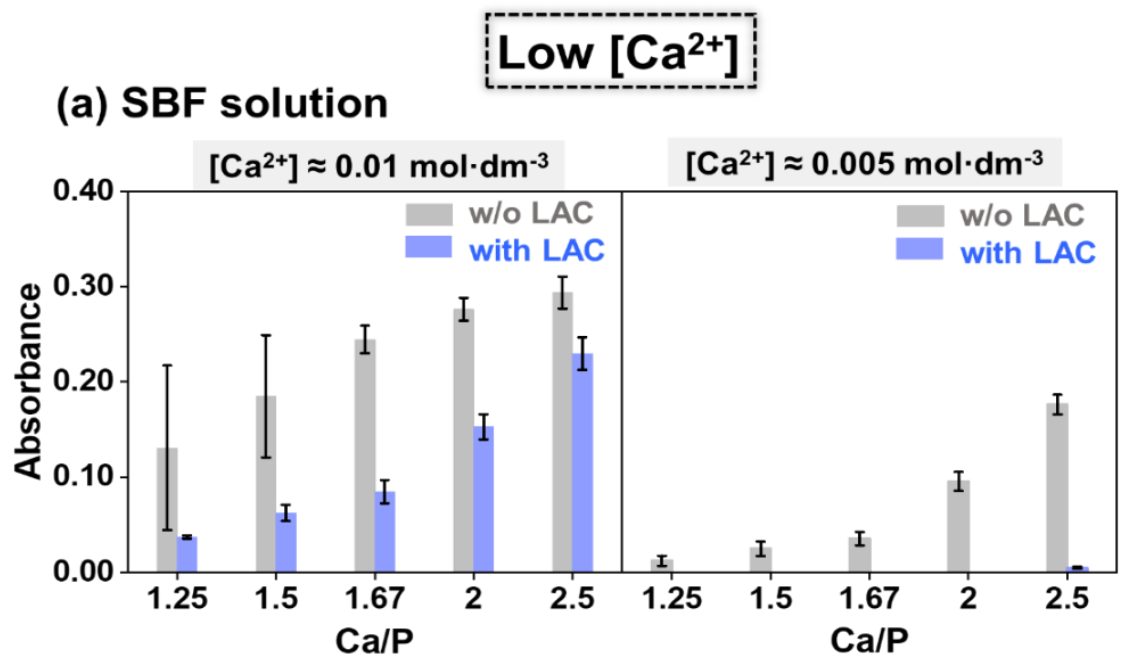

(b) Aqueous solution

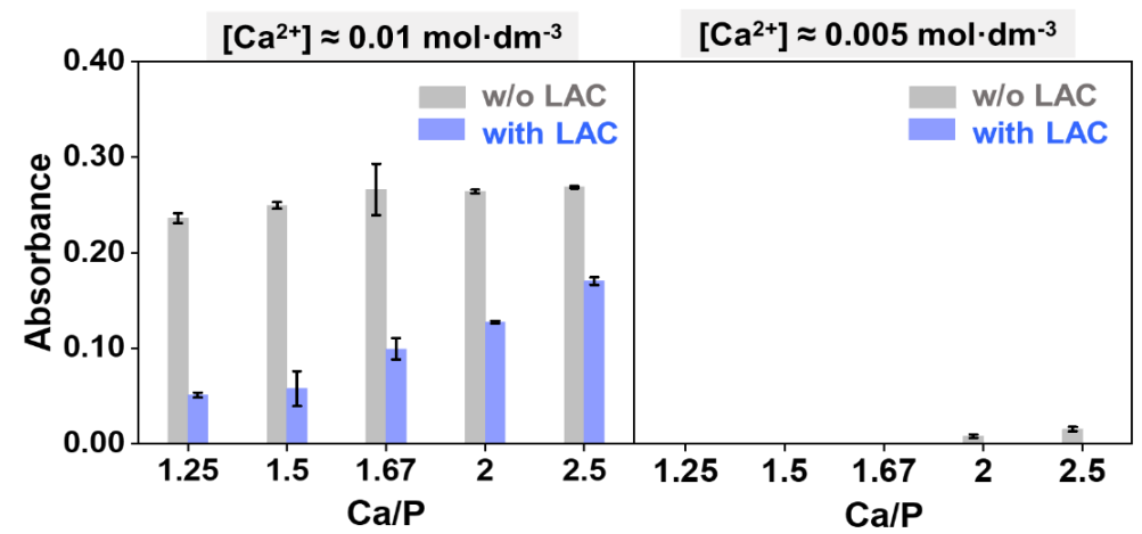

Figure 9. The UV-Vis absorbance values at $450 \mathrm{~nm}$ of 120 experimental groups with different $\mathrm{Ca} / \mathrm{P}$ ratios under (a) SBF solution and (b) aqueous solution before and after adding $\mathrm{LAC}(\mathrm{pH} \approx 7.4)$, where the $\left[\mathrm{Ca}^{2+}\right]$ are about $0.01 \mathrm{~mol} \cdot \mathrm{dm}^{-3}$ (left) and 0.005 $\mathrm{mol} \cdot \mathrm{dm}^{-3}$ (right), respectively. 
The as-prepared samples showed the plate-like morphology with nanoscale size by TEM (Figure 10c and Figure S26). Although the different preparation methods including reaction time (stiring time), sequence of adding solutions, and w/o or with LAC additive, the major compositions of as-prepared samples were DCPD. The presence of LAC induced slight difference in the DCPD morphology (Figure 10c). Moreover, the addition of LAC made the solution acidic without adjusting intial $\mathrm{pH}$ value, which matchs well with the reported $\mathrm{pH}$ conditions $(\mathrm{pH}=2.0 \sim 6.0)$ for obtaining DCPD product ${ }^{4,8}$. The prepared DCPD with the (stirring) reaction time of $0.25 \mathrm{~h}$ is kinetically stable for days and even months. The XRD and TEM data were observed after $24 \mathrm{~h}$ of drying in a vacuum oven.

High $\left[\mathrm{Ca}^{2+}\right]$ concentration. We continued to increase the $\left[\mathrm{Ca}^{2+}\right]$ concentration to $0.3 \mathrm{~mol} \cdot \mathrm{dm}^{-3}$ with different $\mathrm{Ca} / \mathrm{P}$ ratios of $1.50,1.67$, and 2.00 , with the XRD, TEM, and zeta potentials of solid-state products shown in Figure 11 . When $\mathrm{Ca} / \mathrm{P}=2.00$, the diffraction peak of the characteristic (020) crystal face (marked with an arrow in Figure 11a) was obviously weakened by the addition of LAC. As shown in Figure 11b, the (020) peak is the most evident at $\mathrm{Ca} / \mathrm{P}=1.67$, which is a unique $\mathrm{Ca} / \mathrm{P}$ ratio in $\mathrm{HA}$. The relatively large sized amorphous plate-like morphologies were observed in TEM pictures (Figure S27). Moreover, the TEM and XRD data of those samples were measured after the storage for 1 month, indicating that those DCPD powders are rather stable at room temperature. 


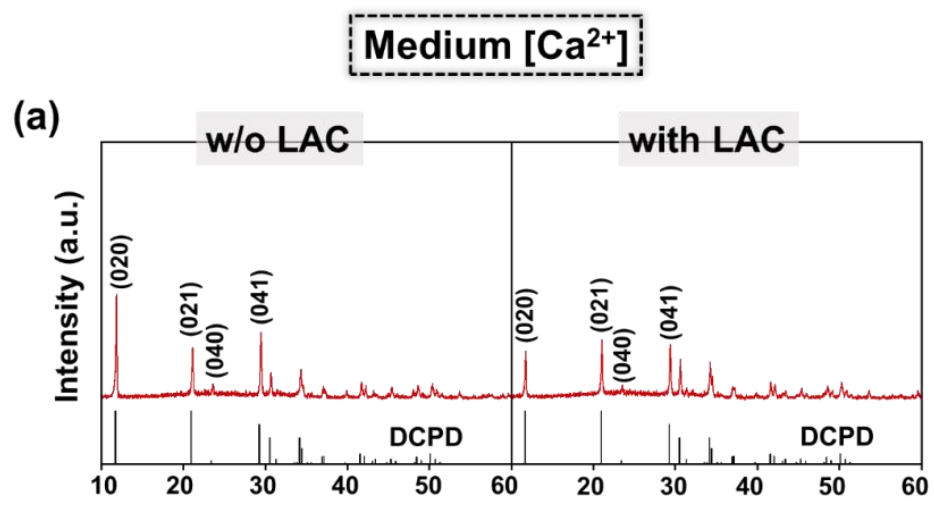

(b)

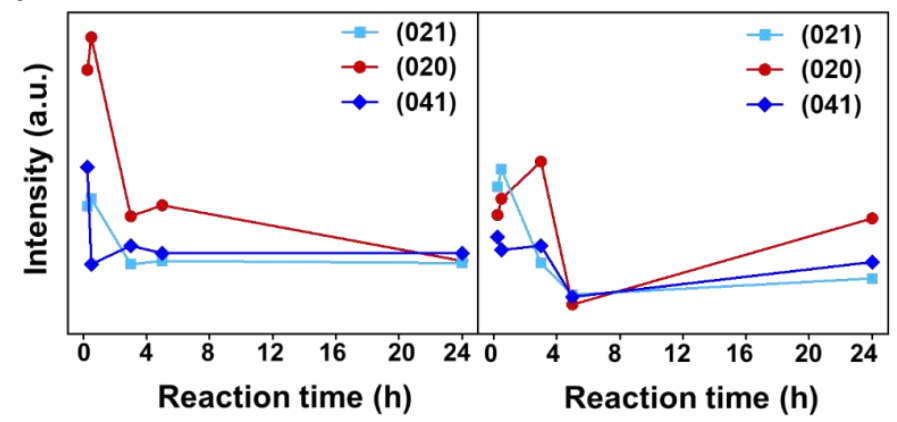

(c)

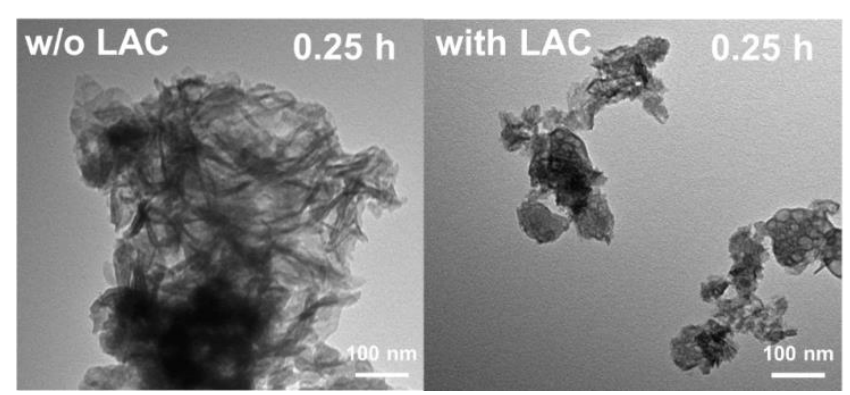

Figure 10. (a) XRD patterns of the as-prepared samples with the reaction time of 0.25 $\mathrm{h}$, (b) intensities of characteristic peaks such as (020), (021), (041) as a function of reaction time from 0 to $24 \mathrm{~h}$, (c) TEM images of DCPD (JCPDS\#09-0077) with the reaction time of $0.25 \mathrm{~h}$.

An interesting transformation from HA into the metastable DCPD phase was observed in presence of $\mathrm{Mg}^{2+}$ ions with the $\left[\mathrm{Mg}^{2+}\right]$ concentration of $0.23 \mathrm{~mol} \cdot \mathrm{dm}^{-3}$, leading into the final product of $\mathrm{WH}\left(\mathrm{Ca}_{18} \mathrm{Mg}_{2}\left(\mathrm{HPO}_{4}\right)_{2}\left(\mathrm{PO}_{4}\right)_{12}\right)$ as the $\mathrm{pH}$ decreases at $70{ }^{\circ} \mathrm{C} .{ }^{14}$ Our DFT calculations in Table S1 indicated that the binding strength of $\mathrm{Mg}^{2+}$ ions with $1 \mathrm{H}$ species $\left(\Delta G_{b i n d}\right.$ of $\left.\mathrm{Mg}\left(\eta^{2}-1 \mathrm{H}\right):-14.09 \mathrm{kcal} / \mathrm{mol}\right)$ is much weaker than that $(-32.16 \mathrm{kcal} / \mathrm{mol})$ of the $\mathrm{Ca}\left(\eta^{2}-1 \mathrm{H}\right)$ cluster, implying the little influence of small amount 
of $\mathrm{Mg}^{2+}$ ions (e.g., about $0.0015 \mathrm{~mol} \cdot \mathrm{dm}^{-3}$ in $\mathrm{SBF}$ solution). To further study the effect of $\mathrm{Mg}^{2+}$ ions on the nucleation process of $\mathrm{CaP}$, we carried out two control experiments under SBF solution and $\mathrm{Ca} / \mathrm{Mg}$-deficient DPBS solution, respectively, with $\mathrm{Ca}^{2+}$ concentration of $0.225 \mathrm{~mol} \cdot \mathrm{dm}^{-3}$. The experimental procedures referred to the medium $\left[\mathrm{Ca}^{2+}\right]$ concentration in S5 of supporting information (Condition iii). The produced DCPD-S sample under SBF solution did not contain Mg element by EDS and ICP analysis (Figure S29 and Table S26), which is same as those characterized for DCPDD (which was obtained from $\mathrm{Ca} / \mathrm{Mg}$-deficient $\mathrm{DPBS}$ solution) and DCPD-C (commercially available sample). As shown in Table S26, the prepared DCPD-S and DCPD-D has little Mg content of less than $0.05 \mathrm{mg} / \mathrm{L}$, even smaller than that $(0.132$ $\mathrm{mg} / \mathrm{L}$ ) in commercial product DCPD-C. It is conceived that only when the concentration of $\mathrm{Mg}^{2+}$ ions is high enough, the effect of competitive binding interactions with phosphates between $\mathrm{Mg}^{2+}$ and $\mathrm{Ca}^{2+}$ ions is standing out. In the physiological conditions (like in neutral SBF solution), the concentration of $\mathrm{Mg}^{2+}$ ions is very low and the effect of $\mathrm{Mg}^{2+}$ ions is negligible. 


\section{High $\left[\mathrm{Ca}^{2+}\right]$}

(a)

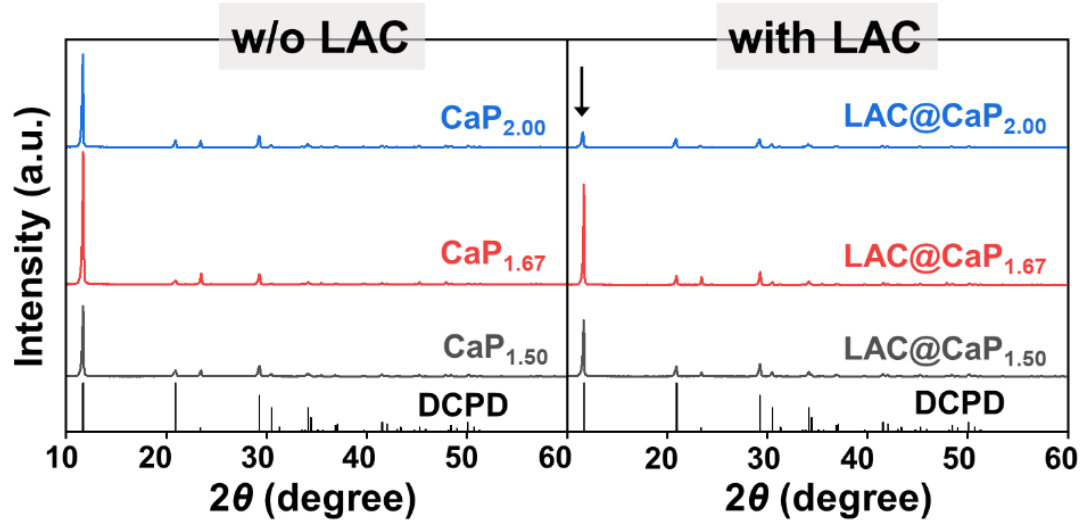

(b)

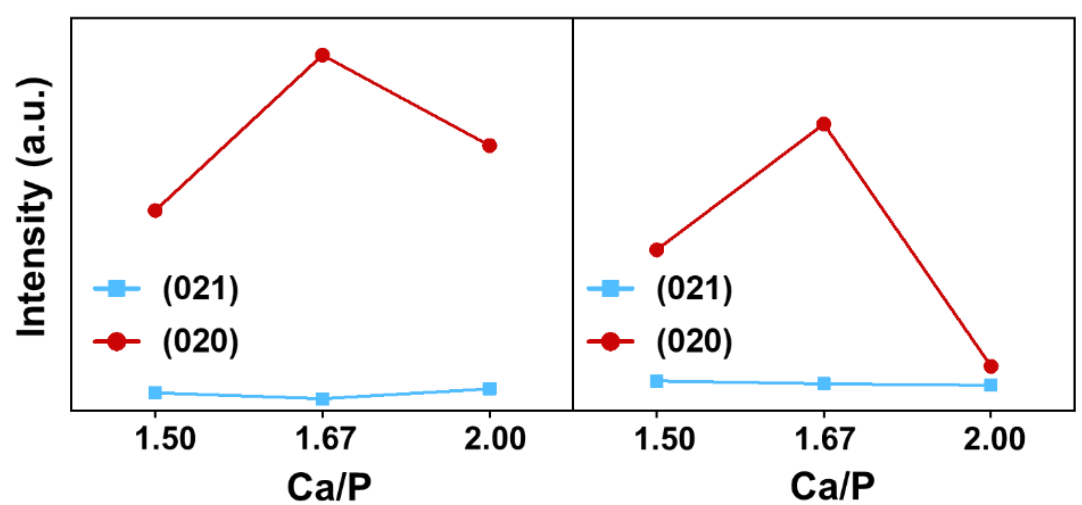

(c)

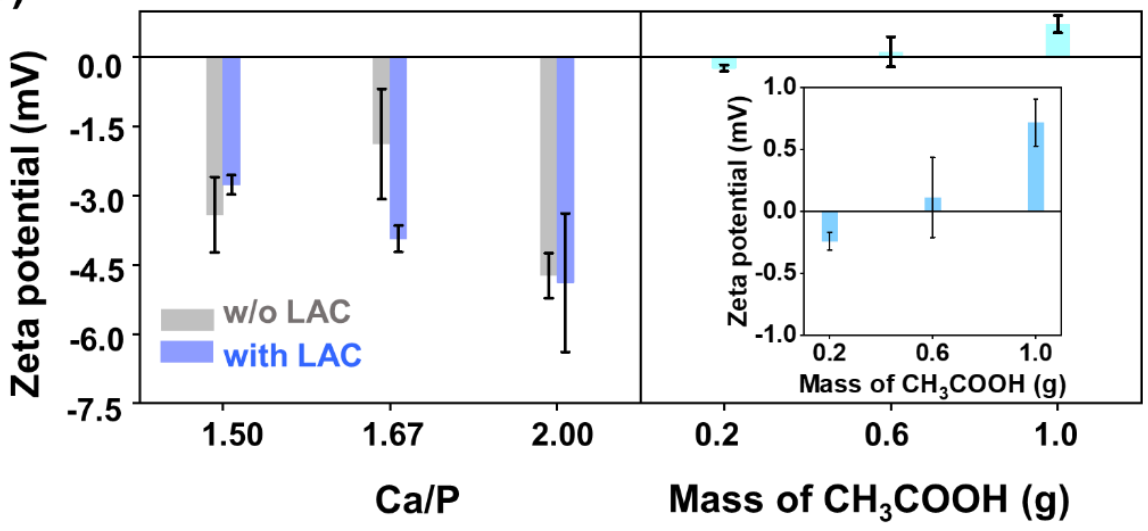

Figure 11. (a) XRD patterns of the samples, formed after $48 \mathrm{~h}$ of freeze drying and stored for about 1 month, (b) intensities of characteristic peaks such as (020), (021) of DCPD (JCPDS\#09-0077), as a function of $\mathrm{Ca} / \mathrm{P}$ ratio, (c) zeta potentials of $\mathrm{CaP}$ with different $\mathrm{Ca} / \mathrm{P}$ ratios and as-prepared samples with different masses of $\mathrm{CH}_{3} \mathrm{COOH}$. 
Zeta potential was used to estimate the average surface electronegativities. We selected three experimental groups $\left(\mathrm{CaP}_{1.50}, \mathrm{CaP}_{1.67}\right.$ and $\left.\mathrm{CaP}_{2.00}\right)$ to measure their zeta potentials. All these three samples had negative zeta potentials (Figure 11c, Table 1), demonstrating that they had net negative surface charges. The presence of LAC caused a slight increase in the zeta potentials of the samples $\mathrm{CaP}_{1.67}$ and $\mathrm{CaP}_{2.00}$. Although the zeta potential values measured by different research groups may be different from each other, the experimental data of various nanoparticles ${ }^{9,45,78-81}$ collected in Table 1 could still give some general trends. Some nanoparticles with negative zeta potentials were found to be efficiently taken up by A375 cells, MG-63 cells, A549 cells and HeLa cells (Table 1). ${ }^{45,79-81}$ The HA particles with several kinds of oxygen-containing addtives ${ }^{10-}$ 12 also exhibited negative zeta potentials, whose values were dependent on the $\mathrm{pH}$ values. In addition to the aforementioned nanoparticles, two-dimensional materials such as arsenene could inhibit the proliferation of NB4 cancer cells (82\% inhibition) with the negative zeta potential $(-17.8 \mathrm{mV}) .{ }^{82}$ Such negative zeta potentials of nanoparticles were proposed to favor osseointegration, apatite nucleation, and inhibition of tumor cell proliferation..$^{9,45,79,81,82}$ It was addressed that highly negative zeta potential contributed to accumulation of $\mathrm{Ca}^{2+}$ ions, which was conductive to bone regeneration, thus enhanced the bioactivity of the nanoparticle. ${ }^{78}$ On the contray, low zeta potential would lead to aggregation or coagulation of nanoparticles, favored by interparticle interaction. To summary, the surface electronegativities and zeta potential could be taken as one of the descriptors in understanding the aggregation and biological functions of $\mathrm{CaP}$ particles. 
Table 1. The zeta potential values of the as-prepared $\mathrm{CaP}$ samples and some other nanoparticles with and without additives.

\begin{tabular}{|c|c|c|c|}
\hline Samples & Zeta potential $(\mathrm{mV})$ & Tumor cells & References \\
\hline \multicolumn{4}{|c|}{$\mathrm{CaP}$ or HA with additives } \\
\hline $\mathrm{LAC}_{\mathrm{C}} \mathrm{CaP}_{1.50}$ & $-2.77 \pm 0.21(\mathrm{pH} \approx 7.4)$ & / & This work \\
\hline LAC@ $\mathrm{CaP}_{1.67}$ & $-3.92 \pm 0.29(\mathrm{pH} \approx 7.4)$ & / & This work \\
\hline LAC@ $\mathrm{CaP}_{2.00}$ & $-4.89 \pm 1.50(\mathrm{pH} \approx 7.4)$ & / & This work \\
\hline Citric acid@HA & $0.00 \sim-50.00(\mathrm{pH}=3 \sim 11)$ & I & 10 \\
\hline Oxalic acid@HA & $0.00 \sim-40.00(\mathrm{pH}=4 \sim 11)$ & / & 11 \\
\hline Malic acid@HA & $0.00 \sim-20.00(\mathrm{pH}=5 \sim 11)$ & / & 12 \\
\hline \multicolumn{4}{|c|}{$\mathrm{CaP}$ or HA nanoparticles w/o additives } \\
\hline $\mathrm{CaP}_{1.50}(\mathrm{Ca} / \mathrm{P}=1.50)$ & $-3.41 \pm 0.82(\mathrm{pH} \approx 7.4)$ & / & This work \\
\hline $\mathrm{CaP}_{1.67}(\mathrm{Ca} / \mathrm{P}=1.67)$ & $-1.88 \pm 1.20(\mathrm{pH} \approx 7.4)$ & / & This work \\
\hline $\mathrm{CaP}_{2.00}(\mathrm{Ca} / \mathrm{P}=2.00)$ & $-4.73 \pm 0.49(\mathrm{pH} \approx 7.4)$ & / & This work \\
\hline $\mathrm{HA}-\mathrm{A}(\mathrm{Ca} / \mathrm{P}=1.67)$ & $-9.62 \pm 0.65(\mathrm{pH} \approx 10.0)$ & A375 cells & 45 \\
\hline $\mathrm{HA}-\mathrm{B}(\mathrm{Ca} / \mathrm{P}=1.67)$ & $-10.90 \pm 0.91(\mathrm{pH} \approx 10.0)$ & A375 cells & 45 \\
\hline $\mathrm{HA}-\mathrm{C}(\mathrm{Ca} / \mathrm{P}=1.67)$ & $-12.50 \pm 0.78(\mathrm{pH} \approx 10.0)$ & A375 cells & 45 \\
\hline $\mathrm{HA}-\mathrm{D}(\mathrm{Ca} / \mathrm{P}=1.67)$ & $-16.60 \pm 0.60(\mathrm{pH} \approx 10.0)$ & A375 cells & 45 \\
\hline $\mathrm{HA}-\mathrm{E}(\mathrm{Ca} / \mathrm{P}=1.67)$ & $-10.60 \pm 0.69(\mathrm{pH} \approx 10.0)$ & A375 cells & 45 \\
\hline $\mathrm{HA}(\mathrm{Ca} / \mathrm{P}=1.21)$ & $-2.0(\mathrm{pH} \approx 7.2)$ & MG-63 cells & 79 \\
\hline $\mathrm{Au} @ \mathrm{HA}$ & $-15.0(\mathrm{pH} \approx 7.2)$ & MG-63 cells & 79 \\
\hline Ag@HA & $-13.4(\mathrm{pH} \approx 7.2)$ & MG-63 cells & 79 \\
\hline Au-Ag@HA & $-11.6(\mathrm{pH} \approx 7.2)$ & MG-63 cells & 79 \\
\hline Ag@HA & $8.0 \sim-25.0(\mathrm{pH}=4 \sim 11)$ & l & 78 \\
\hline F-Cl@HA & $-17.0 \sim-37.0(\mathrm{pH}=5,7.4,9)$ & / & 9 \\
\hline \multicolumn{4}{|c|}{ Other nanoparticles } \\
\hline $\mathrm{Au}-\mathrm{NP}$ & $-31.5(\mathrm{pH} \approx 7.2)$ & MG-63 cells & 79 \\
\hline $\mathrm{Ag}-\mathrm{NP}$ & $-26.72(\mathrm{pH} \approx 7.2)$ & MG-63 cells & 79 \\
\hline $\mathrm{Au}-\mathrm{Ag}-\mathrm{NP}$ & $-5.93(\mathrm{pH} \approx 7.2)$ & MG-63 cells & 79 \\
\hline Cerium oxide-1 & $-16.26(\mathrm{pH} \approx 7.0)$ & A549 cells & 80 \\
\hline Cerium oxide-2 & $-43.10(\mathrm{pH} \approx 13.0)$ & A549 cells & 80 \\
\hline Cerium oxide-5 & $-42.46(\mathrm{pH} \approx 13.0)$ & A549 cells & 80 \\
\hline Iron oxide & $-9.0 \sim-45.0(\mathrm{pH}=1 \sim 13)$ & HeLa cells & 81 \\
\hline
\end{tabular}

Very high $\left[\mathrm{Ca}^{2+}\right]$ concentration. We used another method to prepare DCPD with the introduction of $\mathrm{CH}_{3} \mathrm{COOH}$ in solutuon, with the preparation process referred to the literature ${ }^{83}$. As shown in Figure $12 \mathrm{a}$, with the increase of mass of $\mathrm{CH}_{3} \mathrm{COOH}$ from 0.1 to $1.0 \mathrm{~g}$, the final precipitate was composed of DCPD and $\mathrm{Ca}(\mathrm{OH})_{2}$, judged by the characteristic XRD peaks (JCPDS\#09-0077 and 44-1481). The intensity of 
characteristic peaks fluctuated greatly when the mass of $\mathrm{CH}_{3} \mathrm{COOH}$ was increased from 0.4 to $0.7 \mathrm{~g}$ (Figure $12 \mathrm{~b}$ ), which again suggested that the nucleation of $\mathrm{CaP}$ was a dynamic process in solution. It was reported that the addition of $\mathrm{CH}_{3} \mathrm{COO}^{-}$anion led to an increase in the amount of $\mathrm{HPO}_{4}{ }^{2-}$, accelerating the formation of DCPD precipitate. ${ }^{8}$ In fact, adding different amounts of $\mathrm{CH}_{3} \mathrm{COOH}$ is also equivalent to adjusting $\mathrm{pH}$ values. As the mass of the added $\mathrm{CH}_{3} \mathrm{COOH}$ increases, the initial $\mathrm{pH}$ value changed from alkaline $(\mathrm{pH}=12.3)$ to acidic condition ( $\mathrm{pH}=5.0$ with $\left.1.0 \mathrm{~g} \mathrm{CH}_{3} \mathrm{COOH}\right)$. The asprepared samples had nearly neutral surface net charges, favoring the formation of powders with good dispersibility (Figure 11c). When the mass of $\mathrm{CH}_{3} \mathrm{COOH}$ was 0.2 $\mathrm{g}(\mathrm{pH}=12.1)$, the sample also contained the HA phase to some extent based on the standard card (JCPDS\#09-0432)'s (002) and (211) reflection (Figure S28a). The composition of other prepared samples was still dominated by DCPD. Their TEM pictures displayed that the products were nano-scaled particles with needle-like or rodlike morphologies (Figure 12c and Figure S28b).

In fact, LAC should also have the similar effect to $\mathrm{CH}_{3} \mathrm{COOH}$ in lowering the $\mathrm{pH}$ value of $\mathrm{CaP}$ solution. The acidic condition was demonstrated to be favorable for the dissolution of DCPD. ${ }^{38}$ To investigate the dissolution of DCPD with and without the addition of LAC, we put the above-mentioned three samples, DCPD-S (from SBF), DCPD-D (from DPBS), DCPD-C (commercial reference) in water at ambient conditions. As shown in Figure S30, in absence of LAC, turbidity was not observed in water after $24 \mathrm{~h}$ and $48 \mathrm{~h}$, which could be understood with the very low solubility of DCPD in water $(\sim 0.088 \mathrm{~g} / \mathrm{L})$ at $25^{\circ} \mathrm{C}^{3,4}$. Both synthetic DCPD in this work and commercially available DCPD are difficult to dissolve without any additives in water. However, when LAC solution was added into the containers consisting of water and three DCPD samples, the DCPD precipitation dissolved within a short period of time (Figure S30). In conclusion, the addition of the large amount of LAC would lower the $\mathrm{pH}$ value to make DCPD kinetically unstable and dissolve in water. It should be mentioned that the concentrations of LAC and $\left[\mathrm{Ca}^{2+}\right]$ are of great importance. In our 'low $\left[\mathrm{Ca}^{2+}\right]$ concentration' experiments (Figure 9) and the dissolution experiments 
(Figure S30), the higher [LAC] concentration $\left(1.14\right.$ and $\left.2.28 \mathrm{~mol} \cdot \mathrm{dm}^{-3}\right)$ but relatively lower $\left[\mathrm{Ca}^{2+}\right]$ concentration $\left(0.01\right.$ and $\left.0.058 \mathrm{~mol} \cdot \mathrm{dm}^{-3}\right)$ prohibited the formation of nucleation from small sized clusters or dissolved those prepared DCPD precipitation. In contrast, in 'high $\left[\mathrm{Ca}^{2+}\right]$ concentration' experiments, gradually increasing the $\left[\mathrm{Ca}^{2+}\right]$ concentration would cause the $\mathrm{Ca}^{2+}$ ions in a supersaturated state, resulting in the formation of DPCD precipitation (Figures 10-12).

(a)

Factor 1

Very high $\left[\mathrm{Ca}^{2+}\right]$ adding of $\mathrm{CH}_{3} \mathrm{COOH}$

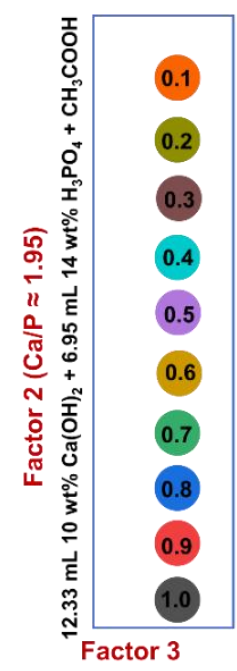

(Aqueous solution) 10

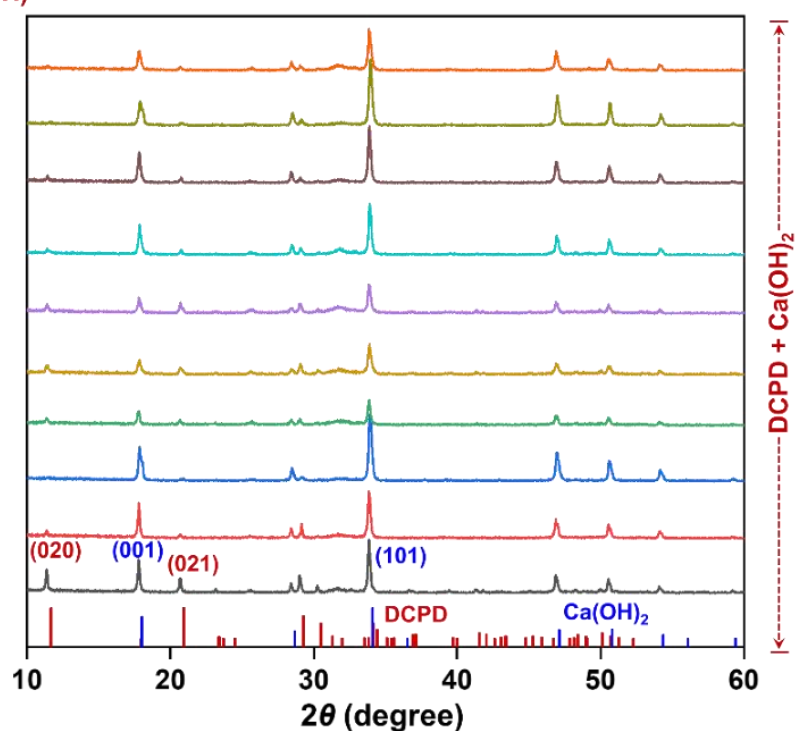

(b)

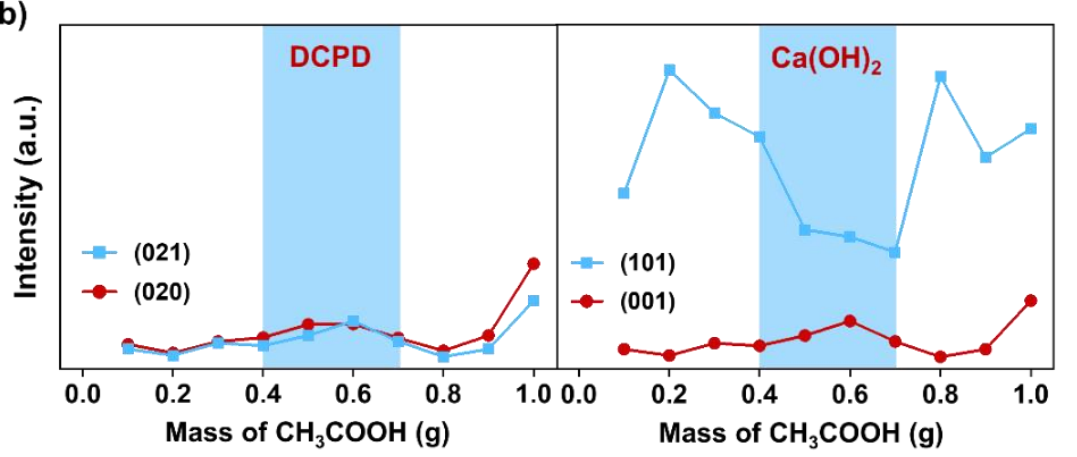

(c)

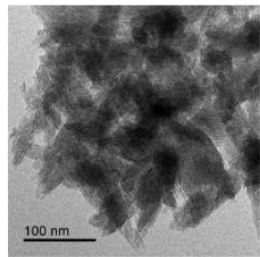

$0.0 \mathrm{~g}$

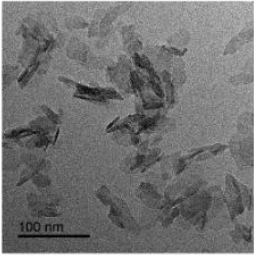

$0.2 \mathrm{~g}$

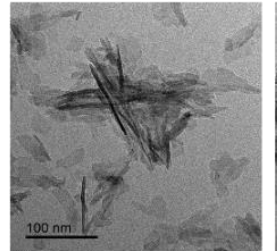

$0.6 \mathrm{~g}$

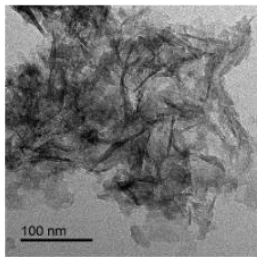

$1.0 \mathrm{~g}\left(\mathrm{CH}_{3} \mathrm{COOH}\right)$
12.1
5.0 
Figure 12. (a) The preparation factors in high-throughput experimentations and XRD spectrum of as-prepared samples, (b) intensities of characteristic peaks such as (020) and (021) surfaces of DCPD (JCPDS\#09-0077), (001) and (101) surfaces of $\mathrm{Ca}(\mathrm{OH})_{2}$ (JCPDS\#44-1481), respectively, changes with the amount of adding $\mathrm{CH}_{3} \mathrm{COOH}$, (c) TEM images of the as-prepared samples with different masses of the added $\mathrm{CH}_{3} \mathrm{COOH}$.

\section{CONCLUSION}

In this work, we have systematically investigated the influence of additives, $\mathrm{Ca} / \mathrm{P}$ ratios, initial $\mathrm{pH}$ values and solvent environments on the nucleation process of $\mathrm{CaP}$, both theoretically and experimentally. The $\mathrm{pH}$-dependent protonation states of phosphate species and their coordination modes with $\mathrm{Ca}^{2+}$ ions were analyzed through DFT, AIMD and MD simulations. A general picture of nucleation was exhibited in terms of an important descriptor, the coordination number of $\mathrm{Ca}^{2+}$ ions. The nucleation of $\mathrm{CaP}$ requires the formation of metastable clusters and aggregates with the increasing coordination number of surface $\mathrm{Ca}^{2+}$ ions. With the addition of LAC in neutral and alkaline conditions, competitive interactions from the oxygen-containing groups in LAC and other ions in SBF solutions with $\mathrm{Ca}^{2+}$ ions and low $\mathrm{pH}$ value reduced the chance of forming $\mathrm{CaP}$ clusters at the early stage of nucleation in dilute solution. With the increasing $\left[\mathrm{Ca}^{2+}\right]$ concentration, the kinetically stable DCPD precipitation was formed with high $\mathrm{Ca}^{2+}$ coordination number and low surface energy. Different morphologies of DCPD precipitation, plate, needle, or rod, were obtained in different experimental conditions. The presence of small amount of LAC could stabilize the nucleation clusters by changing the Ca-exposed surface into the phosphate-exposed or LAC covered surface, promoting the formation of DCPD in solution. The prepared samples at $\mathrm{pH} \approx 7.4$ with different $\mathrm{Ca} / \mathrm{P}$ ratios exhibited negative zeta potential values, which were correlated with the surface electrostatic potential distributions and potential biological functions (such as inhibition of tumor cell proliferation). Understanding the influences of additive, initial $\mathrm{pH}$ value, and $\left[\mathrm{Ca}^{2+}\right]$ concentration on the nucleation 
process of $\mathrm{CaP}$ is useful to guide the rational design of potential antitumor or tissue regeneration materials.

\section{ASSOCIATED CONTENTS}

\section{Supporting Information}

Calculated binding free energies; optimized structures of $\mathrm{CaP}$ clusters and DCPD/HA surfaces; surface energies of DCPD/HA surfaces; distribution coefficient $\delta$ of carbonate species and LAC; force field parameters of phosphate species, number of ions and water molecules of the $\mathrm{CaP}$ systems; ions concentration for high-throughput experimentations in aqueous solution and SBF solution; MD snapshots, SDF and RDF

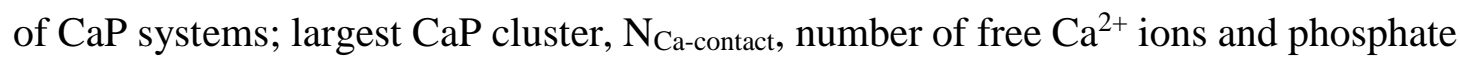
species of $\mathrm{CaP}$ systems; contents of $\mathrm{Ca}$ and $\mathrm{Mg}$, XRD patterns, TEM images, SEM images and EDS patterns of prepared samples.

\section{ACKNOWLEDGEMENTS}

This work was supported by the National Key Research and Development Program of China (2017YFB0702601, 2017YFB0702602), the National Natural Science Foundation of China (grant nos. 21873045, 22033004, 21773112). We are grateful to the High Performance Computing Centre of Nanjing University for providing the IBM Blade cluster system.

\section{Author Contributions}

J.M. and H.C. designed all the computations. C.L., L.G., X.L., and X.G conceived the experiments and performed characterizations (XRD, TEM, SEM, UV-Vis, Zeta potential, EDS and ICP). M.M., Z.L., J.L., H.C., and X.Z. guided the high-throughput experimentations. J.H., H.D., Q.Z., Y.G., and Z.L provided the data analysis scripts. All authors contributed to discussing the results as well as the writing and revising of the manuscript. 


\section{Notes}

The authors declare no competing financial interest.

\section{REFERENCES}

(1) Nudelman, F.; Sommerdijk, N. A. Biomineralization as an inspiration for materials chemistry. Angew. Chem. Int. Ed. 2012, 51 (27), 6582-6596.

(2) Erdemir, D.; Lee, A. Y.; Myerson, A. S. Nucleation of crystals from solution: classical and two-step models. Acc. Chem. Res. 2009, 42 (5), 621-629.

(3) Dorozhkin, S. V. Calcium orthophosphates: occurrence, properties, biomineralization, pathological calcification and biomimetic applications. Biomatter 2011, 1 (2), 121-164.

(4) Dorozhkin, S. V. Calcium orthophosphates $\left(\mathrm{CaPO}_{4}\right)$ : occurrence and properties. Prog. Biomater. 2016, 5 (1), 9-70.

(5) Wei, W.; Zhang, X.; Cui, J.; Wei, Z. Interaction between low molecular weight organic acids and hydroxyapatite with different degrees of crystallinity. Colloid Surf. A: Physocochem. Eng. Aspects 2011, $392(1), 67-75$.

(6) Sadat-Shojai, M.; Khorasani, M.-T.; Jamshidi, A. Hydrothermal processing of hydroxyapatite nanoparticles-A Taguchi experimental design approach. J. Cryst. Growth 2012, 361, 73-84.

(7) Wang, P.; Li, C.; Gong, H.; Jiang, X.; Wang, H.; Li, K. Effects of synthesis conditions on the morphology of hydroxyapatite nanoparticles produced by wet chemical process. Powder Technol. 2010, 203 (2), 315-321.

(8) Hamai, R.; Toshima, T.; Tafu, M.; Masutani, T.; Chohji, T. In Effect of anions on morphology control of brushite particles, Key Eng. Mater. 2013, 529, 55-60.

(9) Fahami, A.; Beall, G. W.; Betancourt, T. Synthesis, bioactivity and zeta potential investigations of chlorine and fluorine substituted hydroxyapatite. Mater. Sci. Eng. C 2016, 59, 78-85.

(10) Skwarek, E.; Janusz, W.; Sternik, D. Adsorption of citrate ions on hydroxyapatite synthetized by various methods. J. Radioanal. Nucl. Chem. 2014, 299 (3), 2027-2036.

(11) Skwarek, E. Thermal analysis of hydroxyapatite with adsorbed oxalic acid. J. Therm. Anal. Calorim. 2015, 122 (1), 33-45.

(12) Janusz, W.; Skwarek, E. Adsorption of malic acid at the hydroxyapatite/aqueous $\mathrm{NaCl}$ solution interface. Appl. Nanosci. 2021, https://doi.org/10.1007/s13204-021-01938-w.

(13) Zou, X.; Zhao, Y.; Zhang, Z. Preparation of hydroxyapatite nanostructures with different morphologies and adsorption behavior on seven heavy metals ions. J. Contam. Hydrol. 2019, 226, 103538 .

(14) Jang, H. L.; Lee, H. K.; Jin, K.; Ahn, H.-Y.; Lee, H.-E.; Nam, K. T. Phase transformation from hydroxyapatite to the secondary bone mineral, whitlockite. J. Mater. Chem. B 2015, 3 (7), 1342-1349.

(15) Tas, A. C.; Bhaduri, S. B. Chemical processing of $\mathrm{CaHPO}_{4} \cdot 2 \mathrm{H}_{2} \mathrm{O}$ : its conversion to hydroxyapatite. J. Am. Ceram. Soc. 2004, 87 (12), 2195-2200.

(16) Furutaka, K.; Monma, H.; Okura, T.; Takahashi, S. Characteristic reaction processes in the system brushite-NaOH solution. J. Eur. Ceram. Soc. 2006, 26 (4-5), 543-547. 
(17) Sun, N.; Jia, Y.; Wang, C.; Xia, J.; Dai, L.; Li, J. Dopamine-Mediated Biomineralization of Calcium Phosphate as a Strategy to Facilely Synthesize Functionalized Hybrids. J. Phys. Chem. Lett. 2021, 12, 10235-10241.

(18) Chu, X.; Jiang, W.; Zhang, Z.; Yan, Y.; Pan, H.; Xu, X.; Tang, R. Unique roles of acidic amino acids in phase transformation of calcium phosphates. J. Phys. Chem. B 2011, 115 (5), 1151-1157.

(19) Jiang, W.; Chu, X.; Wang, B.; Pan, H.; Xu, X.; Tang, R. Biomimetically triggered inorganic crystal transformation by biomolecules: a new understanding of biomineralization. J. Phys. Chem. B 2009, 113 (31), 10838-10844.

(20) Habraken, W. J.; Tao, J.; Brylka, L. J.; Friedrich, H.; Bertinetti, L.; Schenk, A. S.; Verch, A.; Dmitrovic, V.; Bomans, P. H.; Frederik, P. M. Ion-association complexes unite classical and nonclassical theories for the biomimetic nucleation of calcium phosphate. Nat. Commun. 2013, 4 (1), 1-12.

(21) Mancardi, G.; Terranova, U.; de Leeuw, N. H. Calcium phosphate prenucleation complexes in water by means of ab initio molecular dynamics simulations. Cryst. Growth Des. 2016, 16 (6), 3353-3358.

(22) Garcia, N. A.; Malini, R. I.; Freeman, C. L.; Demichelis, R.; Raiteri, P.; Sommerdijk, N. A.; Harding, J. H.; Gale, J. D. Simulation of calcium phosphate prenucleation clusters in aqueous solution: Association beyond ion pairing. Cryst. Growth Des. 2019, 19 (11), 6422-6430.

(23) Malini, R. I.; Freeman, C.; Harding, J. Interaction of stable aggregates drives the precipitation of calcium phosphate in supersaturated solutions. CrystEngComm 2019, 21 (42), 6354-6364.

(24) Yang, X.; Wang, M.; Yang, Y.; Cui, B.; Xu, Z.; Yang, X. Physical origin underlying the prenucleation-cluster-mediated nonclassical nucleation pathways for calcium phosphate. Phys. Chem. Chem. Phys. 2019, 21 (27), 14530-14540.

(25) Dorozhkin, S. V. Amorphous calcium (ortho) phosphates. Acta. Biomater. 2010, 6 (12), 4457-4475.

(26) Xie, B.; Halter, T. J.; Borah, B. M.; Nancollas, G. H. Tracking amorphous precursor formation and transformation during induction stages of nucleation. Cryst. Growth Des. 2014, 14 (4), 1659-1665.

(27) Mancardi, G.; Tamargo, C. E. H.; Di Tommaso, D.; De Leeuw, N. H. Detection of Posner's clusters during calcium phosphate nucleation: a molecular dynamics study. J. Mater. Chem. B 2017, 5 (35), 72747284.

(28) Wang, Y.-W.; Christenson, H. K.; Meldrum, F. C. Confinement increases the lifetimes of hydroxyapatite precursors. Chem. Mater. 2014, 26 (20), 5830-5838.

(29) LeGeros, R. Formation and transformation of calcium phosphates: relevance to vascular calcification. Z. Kardiol. 2001, 90 (3), 116-124.

(30) O'neill, W. The fallacy of the calcium-phosphorus product. Kidney Int. 2007, 72 (7), 792-796.

(31) Dorozhkin, S. V. Dental applications of calcium orthophosphates $\left(\mathrm{CaPO}_{4}\right)$. J. Dentistry Res 2019, 1, 024-54.

(32) Fathi, M.; Kholtei, A.; Youbi, S. E.; El Idrissi, B. C. Setting properties of calcium phosphate bone cement. Mater. Today: Proceed. 2019, 13, 876-881.

(33) Rattanachan, S.; Lorprayoon, C.; Boonphayak, P. Synthesis of chitosan/brushite powders for bone cement composites. J. Ceram. Soc. Jpn. 2008, 116 (1349), 36-41.

(34) Toshima, T.; Hamai, R.; Tafu, M.; Takemura, Y.; Fujita, S.; Chohji, T.; Tanda, S.; Li, S.; Qin, G. Morphology control of brushite prepared by aqueous solution synthesis. J. Asian Ceram. Soc. 2014, 2 (1), 52-56. 
(35) Ngankam, P.; Schaaf, P.; Voegel, J.; Cuisinier, F. Heterogeneous nucleation of calcium phosphate salts at a solid/liquid interface examined by scanning angle reflectometry. J. Cryst. Growth 1999, 197 (4), 927-938.

(36) Sivakumar, G.; Girija, E.; Narayana Kalkura, S.; Subramanian, C. Crystallization and characterization of calcium phosphates: brushite and monetite. Cryst. Res. Technol. 1998, 33 (2), $197-$ 205.

(37) Sørensen, J. S.; Madsen, H. E. L. The influence of magnetism on precipitation of calcium phosphate. J. Cryst. Growth 2000, 216 (1-4), 399-406.

(38) Tang, R.; Hass, M.; Wu, W.; Gulde, S.; Nancollas, G. H. Constant composition dissolution of mixed phases: II. Selective dissolution of calcium phosphates. J. Colloid Interface Sci. 2003, 260 (2), 379-384. (39) Landin, M.; Rowe, R.; York, P. Structural changes during the dehydration of dicalcium phosphate dihydrate. Eur. J. Pharm. Sci. 1994, 2 (3), 245-252.

(40) Sutter, J.; McDowell, H.; Brown, W. E. Solubility study of calcium hydrogen phosphate. Ion-pair formation. Inorg. Chem. 1971, 10 (8), 1638-1643.

(41) Hamad, K.; Kaseem, M.; Yang, H.; Deri, F.; Ko, Y. Properties and medical applications of polylactic acid: A review. Express Polym. Lett. 2015, 9 (5), 435-455.

(42) Meena, R.; Kesari, K. K.; Rani, M.; Paulraj, R. Effects of hydroxyapatite nanoparticles on proliferation and apoptosis of human breast cancer cells (MCF-7). J. Nanopart. Res. 2012, 14 (2), 712.

(43) Sun, Y.; Chen, Y.; Ma, X.; Yuan, Y.; Liu, C.; Kohn, J.; Qian, J. Mitochondria-targeted hydroxyapatite nanoparticles for selective growth inhibition of lung cancer in vitro and in vivo. ACS Appl. Mater. Inter. 2016, 8 (39), 25680-25690.

(44) Cui, X.; Liang, T.; Liu, C.; Yuan, Y.; Qian, J. Correlation of particle properties with cytotoxicity and cellular uptake of hydroxyapatite nanoparticles in human gastric cancer cells. Mater. Sci. Eng. C 2016, 67, 453-460.

(45) Wu, H.; Li, Z.; Tang, J.; Yang, X.; Zhou, Y.; Guo, B.; Wang, L.; Zhu, X.; Tu, C.; Zhang, X. The in vitro and in vivo anti-melanoma effects of hydroxyapatite nanoparticles: influences of material factors. Int. J. Nanomed. 2019, 14, 1177-1191.

(46) Chu, S.-H.; Feng, D.-F.; Ma, Y.-B.; Li, Z.-Q. Hydroxyapatite nanoparticles inhibit the growth of human glioma cells in vitro and in vivo. Int. J. Nanomed. 2012, 7, 3659-3666.

(47) Khalifehzadeh, R.; Arami, H. Biodegradable calcium phosphate nanoparticles for cancer therapy. Adv. Colloid Interface Sci. 2020, 279, 102157.

(48) Colegio, O. R.; Chu, N.-Q.; Szabo, A. L.; Chu, T.; Rhebergen, A. M.; Jairam, V.; Cyrus, N.; Brokowski, C. E.; Eisenbarth, S. C.; Phillips, G. M. Functional polarization of tumour-associated macrophages by tumour-derived lactic acid. Nature 2014, 513 (7519), 559-563.

(49) Marchiq, I.; Pouysségur, J. Hypoxia, cancer metabolism and the therapeutic benefit of targeting lactate/H+ $\mathrm{H}^{+}$symporters. J. Mol. Med. 2016, 94 (2), 155-171.

(50) Shevlin, M. Practical high-throughput experimentation for chemists. ACS Med. Chem. Lett. 2017, 8 (6), 601-607.

(51) Liu, Z.; Shi, Y.; Chen, H.; Qin, T.; Zhou, X.; Huo, J.; Dong, H.; Yang, X.; Zhu, X.; Chen, X. Machine learning on properties of multiscale multisource hydroxyapatite nanoparticles datasets with different morphologies and sizes. npj Comput. Mater. 2021, 7 (1), 1-11.

(52) Gaussian 16, R. A., Frisch, M. J.; Trucks, G. W.; Schlegel, H. B.; Scuseria, G. E.; Robb, M. A.; Cheeseman, J. R.; Scalmani, G.; Barone, V.; Petersson, G. A.; Nakatsuji, H.; Li, X.; Caricato, M.; 
Marenich, A. V.; Bloino, J.; Janesko, B. G.; Gomperts, R.; Mennucci, B.; Hratchian, H. P.; Ortiz, J. V.; Izmaylov, A. F.; Sonnenberg, J. L.; Williams-Young, D.; Ding, F.; Lipparini, F.; Egidi, F.; Goings, J.; Peng, B.; Petrone, A.; Henderson, T.; Ranasinghe, D.; Zakrzewski, V. G.; Gao, J.; Rega, N.; Zheng, G.; Liang, W.; Hada, M.; Ehara, M.; Toyota, K.; Fukuda, R.; Hasegawa, J.; Ishida, M.; Nakajima, T.; Honda, Y.; Kitao, O.; Nakai, H.; Vreven, T.; Throssell, K.; Montgomery, J. A., Jr.; Peralta, J. E.; Ogliaro, F.; Bearpark, M. J.; Heyd, J. J.; Brothers, E. N.; Kudin, K. N.; Staroverov, V. N.; Keith, T. A.; Kobayashi, R.; Normand, J.; Raghavachari, K.; Rendell, A. P.; Burant, J. C.; Iyengar, S. S.; Tomasi, J.; Cossi, M.; Millam, J. M.; Klene, M.; Adamo, C.; Cammi, R.; Ochterski, J. W.; Martin, R. L.; Morokuma, K.; Farkas, O.; Foresman, J. B.; Fox, D. J. Gaussian, Inc., Wallingford CT, 2016.

(53) Kresse, G.; Furthmüller, J. Efficient iterative schemes for ab initio total-energy calculations using a plane-wave basis set. Phys. Rev. B 1996, 54 (16), 11169.

(54) Kresse, G.; Furthmüller, J. Efficiency of ab-initio total energy calculations for metals and semiconductors using a plane-wave basis set. Comp. Mater. Sci. 1996, 6 (1), 15-50.

(55) Grimme, S.; Antony, J.; Ehrlich, S.; Krieg, H. A consistent and accurate ab initio parametrization of density functional dispersion correction (DFT-D) for the 94 elements H-Pu. J. Chem. Phys. 2010, 132 (15), 154104.

(56) Case, D. A.; Cerutti, D. S.; Cheatham, T. E., III; Darden, T. A.; Duke, R. E.; Giese, T. J.; Gohlke, H.; Goetz, A. W.; Greene, D.; Homeyer, N.; Izadi, S.; Kovalenko, A.; Lee, T. S.; LeGrand, S.; Li, P.; Lin, C.; Liu, J.; Luchko, T.; Luo, R.; Mermelstein, D.; Merz, K. M.; Monard, G.; Nguyen, H.; Omelyan, I.; Onufriev, A.; Pan, F.; Qi, R.; Roe, D. R.; Roitberg, A.; Sagui, R.; Simmerling, C. L.; Botello-Smith, W. M.; Swails, J.; Walker, R. C.; Wang, J.; Wolf, R. M.; Wu, X.; Xiao, L.; York, D. M.; Kollman, P. A. Amber 2016. University of California: San Francisco, CA, 2016.

(57) Narendranath, N.; Thomas, K.; Ingledew, W. Effects of acetic acid and lactic acid on the growth of Saccharomyces cerevisiae in a minimal medium. J. Ind. Microbiol. Biotechnol. 2001, 26 (3), 171-177. (58) Siparsky, G. L.; Voorhees, K. J.; Miao, F. Hydrolysis of polylactic acid (PLA) and polycaprolactone (PCL) in aqueous acetonitrile solutions: autocatalysis. J. Environ. Polym. Degr. 1998, 6 (1), 31-41.

(59) Kim, M. S.; Choi, Y.; Fernandez, N. J.; Sponza, A. D.; Navarro, A. E. Biosorption of phosphate by novel biomaterials: an asset against eutrophication of water resources. Biotechnology 2014, 8, 26-34.

(60) Damar, S.; Balaban, M. O. Review of dense phase $\mathrm{CO}_{2}$ technology: microbial and enzyme inactivation, and effects on food quality. J. Food Sci. 2006, 71 (1), R1-R11.

(61) Joshi, R. Charge transfer reactions from tryptophan and tyrosine to sulfur-centered dimer radical cation in aqueous-sulfuric acid medium: a pulse radiolysis study. J. Phys. Org. Chem. 2016, 29 (6), 281287.

(62) Humphrey, W.; Dalke, A.; Schulten, K. VMD: visual molecular dynamics. J. Mol. Graph. 1996, 14 (1), 33-38.

(63) Brehm, M.; Thomas, M.; Gehrke, S.; Kirchner, B. TRAVIS-A free analyzer for trajectories from molecular simulation. J. Chem. Phys. 2020, 152 (16), 164105.

(64) Baker, N. A.; Sept, D.; Joseph, S.; Holst, M. J.; McCammon, J. A. Electrostatics of nanosystems: application to microtubules and the ribosome. Proc. Natl. Acad. Sci. USA 2001, 98 (18), 10037-10041.

(65) Kühne, T. D.; Iannuzzi, M.; Del Ben, M.; Rybkin, V. V.; Seewald, P.; Stein, F.; Laino, T.; Khaliullin, R. Z.; Schütt, O.; Schiffmann, F. CP2K: An electronic structure and molecular dynamics software package-Quickstep: Efficient and accurate electronic structure calculations. J. Chem. Phys. 2020, 152 (19), 194103. 
(66) VandeVondele, J.; Hutter, J. Gaussian basis sets for accurate calculations on molecular systems in gas and condensed phases. J. Chem. Phys. 2007, 127 (11), 114105.

(67) Martínez, L.; Andrade, R.; Birgin, E. G.; Martínez, J. M. PACKMOL: a package for building initial configurations for molecular dynamics simulations. J. Comput. Chem. 2009, 30 (13), 2157-2164.

(68) Habraken, W.; Habibovic, P.; Epple, M.; Bohner, M. Calcium phosphates in biomedical applications: materials for the future? Mater. Today 2016, 19 (2), 69-87.

(69) Eanes, E.; Meyer, J. The maturation of crystalline calcium phosphates in aqueous suspensions at physiologic pH. Calcif. Tissue Res. 1977, 23 (1), 259-269.

(70) De Maeyer, E. A.; Verbeeck, R. M.; Vercruysse, C. W. Conversion of octacalcium phosphate in calcium phosphate cements. J. Biomed. Mater. Res. 2000, 52 (1), 95-106.

(71) Zhang, H.; Darvell, B. W. Morphology and structural characteristics of hydroxyapatite whiskers: effect of the initial Ca concentration, Ca/P ratio and pH. Acta. Biomater. 2011, 7 (7), 2960-2968.

(72) Materials Studio, version 7.0; Accelrys Inc.: San Diego, 2013.

(73) Xue, Z.; Yang, M.; Xu, D. Nucleation of biomimetic hydroxyapatite nanoparticles on the surface of type I collagen: molecular dynamics investigations. J. Phys. Chem. C 2019, 123 (4), 2533-2543.

(74) Zhu, C.; Zhou, X.; Liu, Z.; Chen, H.; Wu, H.; Yang, X.; Zhu, X.; Ma, J.; Dong, H. The morphology of hydroxyapatite nanoparticles regulates cargo recognition in clathrin-mediated endocytosis. Front. Mol. Biosci. 2021, 8, 627015.

(75) Yin, X.; Stott, M. J. Biological calcium phosphates and Posner's cluster. J. Chem. Phys. 2003, 118 (8), 3717-3723.

(76) Lu, X.; Leng, Y. Theoretical analysis of calcium phosphate precipitation in simulated body fluid. Biomaterials 2005, 26 (10), 1097-1108.

(77) Kannan, M. B.; Orr, L. In vitro mechanical integrity of hydroxyapatite coated magnesium alloy. Biomed. Mater. 2011, 6 (4), 045003.

(78) Sakthivel, N.; Socrates, R.; Shanthini, G.; Rajaram, A.; Kalkura, S. N. Silver ion impregnated composite biomaterial optimally prepared using zeta potential measurements. Mater. Sci. Eng. C 2015, 47, 222-229.

(79) Kim, H.; Mondal, S.; Jang, B.; Manivasagan, P.; Moorthy, M. S.; Oh, J. Biomimetic synthesis of metal-hydroxyapatite (Au-HAp, Ag-HAp, Au-Ag-HAp): Structural analysis, spectroscopic characterization and biomedical application. Ceram. Int. 2018, 44 (16), 20490-20500.

(80) Patil, S.; Sandberg, A.; Heckert, E.; Self, W.; Seal, S. Protein adsorption and cellular uptake of cerium oxide nanoparticles as a function of zeta potential. Biomaterials 2007, 28 (31), 4600-4607.

(81) Villanueva, A.; Canete, M.; Roca, A. G.; Calero, M.; Veintemillas-Verdaguer, S.; Serna, C. J.; del Puerto Morales, M.; Miranda, R. The influence of surface functionalization on the enhanced internalization of magnetic nanoparticles in cancer cells. Nanotechnology 2009, 20 (11), 115103.

(82) Wang, X.; Hu, Y.; Mo, J.; Zhang, J.; Wang, Z.; Wei, W.; Li, H.; Xu, Y.; Ma, J.; Zhao, J. Arsenene: a potential therapeutic agent for acute promyelocytic leukaemia cells by acting on nuclear proteins. Angew. Chem. Int. Ed. 2020, 59 (13), 5151-5158.

(83) Tan, S.; Chen, S.; Wang, Y.; Wu, F.; Shi, Y.; Wang, J.; Du, Y.; Zhang, S. Enhanced effect of nanomonetite hydrosol on dentin remineralization and tubule occlusion. Dent. Mater. 2020, 36 (6), 816-825. 


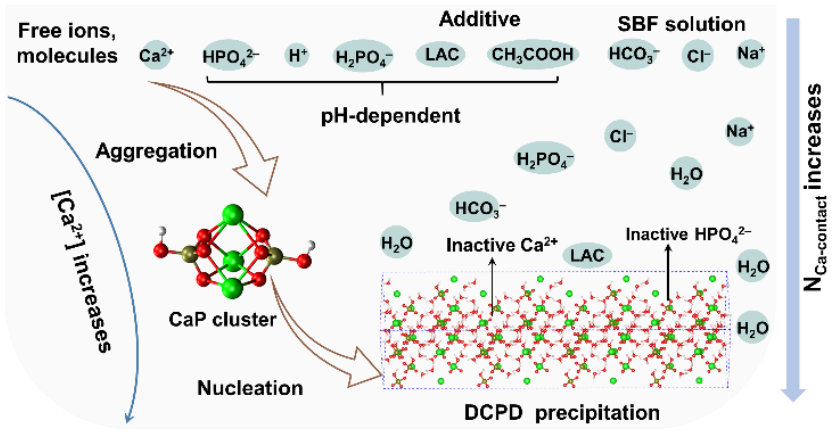

TOC graphic 